\title{
Measuring long chain alkanes in diesel engine exhaust by thermal desorption PTR-MS
}

\author{
M. H. Erickson, M. Gueneron, and B. T. Jobson \\ Laboratory for Atmospheric Research, Department of Civil and Environmental Engineering, Washington State University, \\ Pullman, WA, USA
}

Correspondence to: B. T. Jobson (tjobson@wsu.edu)

Received: 7 June 2013 - Published in Atmos. Meas. Tech. Discuss.: 1 July 2013

Revised: 3 December 2013 - Accepted: 9 December 2013 - Published: 27 January 2014

\begin{abstract}
A method using thermal desorption sampling and analysis by proton transfer reaction mass spectrometry (PTRMS) to measure long chain alkanes $\left(\mathrm{C}_{12}-\mathrm{C}_{18}\right)$ and other larger organics associated with diesel engine exhaust emissions is described. Long chain alkanes undergo dissociative proton transfer reactions forming a series of fragment ions with formula $\mathrm{C}_{n} \mathrm{H}_{2 n+1}$. The PTR-MS is insensitive to $\mathrm{n}$ alkanes less than $\mathrm{C}_{8}$ but displays an increasing sensitivity for larger alkanes. Fragment ion distribution and sensitivity is a function of drift conditions. At $80 \mathrm{Td}$ the most abundant ion fragments from $\mathrm{C}_{10}$ to $\mathrm{C}_{16} \mathrm{n}$-alkanes were $m / z 57$, 71 and 85. The mass spectrum of gasoline and diesel fuel at $80 \mathrm{Td}$ displayed ion group patterns that can be related to known fuel constituents, such as alkanes, alkylbenzenes and cycloalkanes, and other compound groups that are inferred from molecular weight distributions such as dihydronapthalenes and naphthenic monoaromatics. It is shown that thermal desorption sampling of gasoline and diesel engine exhausts at $80 \mathrm{Td}$ allows for discrimination against volatile organic compounds, allowing for quantification of long chain alkanes from the abundance of $\mathrm{C}_{n} \mathrm{H}_{2 n+1}$ fragment ions. The total abundance of long chain alkanes in diesel engine exhaust was measured to be similar to the total abundance of $\mathrm{C}_{1}-\mathrm{C}_{4}$ alkylbenzene compounds. The abundance patterns of compounds determined by thermal desorption sampling may allow for emission profiles to be developed to better quantify the relative contributions of diesel and gasoline exhaust emissions on organic compounds concentrations in urban air.
\end{abstract}

\section{Introduction}

Vehicle emissions are a major source of primary air pollutants that impact human health (HEI, 2010). Photochemical processing of organic compounds from vehicle emissions also forms ozone and increases organic particulate matter concentrations through the formation of secondary organic aerosol (SOA) (Meng et al., 1997). While the photochemistry of ozone formation is reasonably well understood, the formation of secondary organic aerosol (SOA) in urban areas is a less understood, more complex process, and it has been noted that some models significantly underestimate organic aerosol concentrations in urban areas compared to observations (de Gouw et al., 2005; Volkamer et al., 2006; Kleinman et al., 2008). This discrepancy may arise from underestimation of SOA formation rates from larger organic compounds emitted from diesel engine vehicles because exhaust emission inventories for organic compounds are biased towards the condensed phase by virtue of how emissions sampling is done (Robinson et al., 2007; Shirvastava et al., 2008). Components of organic particulate matter emitted from diesel exhaust likely partition back to the gas phase as the exhaust plume becomes diluted, creating a pool of compounds that act as precursors for SOA, which would not be accounted for in emission inventories and chemical transport models (Robinson et al., 2007). These compounds have been labeled intermediate volatile organic compounds (IVOCs) to distinguish them from more volatile organic compounds (VOCs) associated with spark ignition engine exhaust. IVOCs are defined as having a saturation vapor pressure between $1.33 \times 10^{-4}$ and $1.33 \times 10^{-1} \mathrm{hPa}\left(10^{-4}\right.$ and $10^{-1}$ Torr) at $25^{\circ} \mathrm{C}$ (Robinson et al., 2007; Presto et al., 2009). For the n-alkanes this vapor 
pressure range corresponds to dodecane $\left(\mathrm{C}_{12}\right)$ through to octadecane $\left(\mathrm{C}_{18}\right)$ and compounds within this vapor pressure range comprise a large fraction of diesel fuel and exhaust (Han et al., 2008; Schauer et al., 1999; Siegl et al., 1999; Gentner et al., 2012). Laboratory tests have shown significant SOA formation from long chain n-alkanes, branched alkanes, and cyclic alkanes found in diesel engine exhaust (Lim and Ziemann, 2005; Jordan et al., 2008; Samy and Zielinska, 2009; Tkacik et al., 2012). Recasting a portion of the primary organic particulate matter emissions from diesel vehicle exhaust as reactive gas phase material indeed results in significantly more SOA and better agreement with measurements (Shirvastava et al., 2008; Dzepina et al., 2009; Murphy and Pandis, 2009; Hodzic et al., 2010; Pye and Seinfeld, 2010). However, the actual emission rates and photochemistry of these compounds is not well understood. The general importance of diesel engine emissions to urban air chemistry is gaining significance in the United States as gasoline engine roadway emissions of $\mathrm{CO}$ and VOCs are steadily decreasing (Parrish et al., 2009, Schneidemesser et al., 2010) while roadway diesel fuel use has been growing significantly compared to gasoline usage (Dallman and Harley, 2010). Recently Gentner et al. (2012) concluded that diesel engine vehicle emissions were more important than gasoline engine vehicle emissions as a source of SOA for urban regions in California. The opposite conclusion was drawn by Bahreini et al. (2012) for SOA formation in the Los Angeles, CA, urban plume. There is a need to better quantify the abundance of organic compounds associated with diesel engine exhausts so that we may better understand their role in urban air photochemistry and health.

It is difficult to identify and quantify IVOC compounds associated with diesel engine exhaust in urban air due to their low concentration, low volatility, and difficulty in resolving such a large number of compounds by gas chromatographic methods (Zielinska et al., 1996). While n-alkanes are among the most abundant individual components of diesel fuel (Gentner et al., 2012; Vendeuvre et al., 2005; Isaacman et al., 2012) and exhaust (Schauer et al., 1999), branched alkanes, cycloalkanes, and monoaromatic compounds are also very abundant and would be expected to be present in urban air, though rarely reported (Lewis et al., 2000). A new method is presented here to quantify the abundance of IVOC compounds using a thermal desorption sampler integrated into a proton transfer reaction mass spectrometer (PTR-MS). The sampling approach is to alternate VOC sampling by the PTR-MS with analysis of heavier organics collected on an adsorbent resin and analyzed by thermal desorption. In this way the abundance of IVOC compounds can be compared to the abundance of VOC compounds using the same principle of measurement. The PTR-MS identifies organics by molecular weight (MW) and could provide valuable information on the relative abundance by molecular weight of $\mathrm{C}_{12}-\mathrm{C}_{18}$ compounds associated with diesel engine exhaust. This paper reports the technical details of the technique, the sensitivity of the PTR-MS to n-alkanes, and measurements of diesel and gasoline engine exhausts by thermal desorption sampling for IVOCs.

\section{Experimental}

\subsection{Thermal desorption sampler}

Figure 1 shows a diagram of the thermal desorption sampler used to collect IVOC compounds. The PTR-MS (Ionicon Analytik) drift tube was modified to have 2 inlets, one for the IVOC thermal desorption sampler and one for VOCs. The thermal desorption sampler used Tenax TA adsorbent resin, providing a means to preconcentrate organic compounds to improve detection and to provide a means to discriminate against the collection of volatile organic compounds that can interfere in the interpretation of the PTR-MS mass spectrum. Approximately 0.175 grams of Tenax TA was packed into a $0.172 \mathrm{~cm}(0.0676 \mathrm{in}$.) ID stainless steel tube. The tube was resistively heated with an $\mathrm{AC}$ current and temperature controlled using a phase angle control module (Nu Wave Technologies) controlled by a PID (proportional integral derivative) algorithm. Mass flow controllers were used to regulate the sample, desorption, and back flush flows through the adsorbent. Dry nitrogen gas was used for desorption and back flush. The Tenax trap was connected to a heated 2-position six-port gas sampling valve (VICI Valco). Another heated mulitposition 4-port valve was used as a stream selector to sample ambient air or zero air (dry $\left.\mathrm{N}_{2}\right)$. The sampler was controlled by a software program (Azeotech DaqFactory) that allowed for automation of the sampling and thermal desorption steps. The Tenax trap was connected to a custommade sample ring on the PTR-MS drift tube by a $0.0254 \mathrm{~cm}$ (0.01 in.) ID tube. The trap was positioned directly above the PTR-MS drift tube and electrically isolated from the sample drift ring. The drift tube was thermostated to $70^{\circ} \mathrm{C}$ using the thermoelectric drift tube heater supplied by Ionicon. For analysis of heavier organics a high temperature resistive glass drift tube would be preferred such as used in Thornberry et al. (2009). Because of limitations on drift tube temperature that could be obtained with our system, all tubing including the inlet line were heat traced to a similar temperature $\left(80^{\circ} \mathrm{C}\right)$ so that the drift tube did not act as a cold spot and become contaminated. The tubing was either electropolished stainless steel (UHP Cardinal) or silica-coated stainless steel tubing (Sulfinert, Restek Corp). The setup allowed for easy switching between the VOC sampling and IVOC desorption sampling with minimal disruption of the drift tube pressure. While the IVOC sample was being collected, the IVOC inlet was shut (S1 closed) and the VOC inlet open (S2 open) to allow for VOC measurement. The VOC sample was dried by passing the sample through a $-30^{\circ} \mathrm{C}$ cold tube, as described in Jobson and McCoskey (2010), and the low abundance of $\mathrm{H}_{2} \mathrm{O}$ vapor in both measurement modes allowed for 


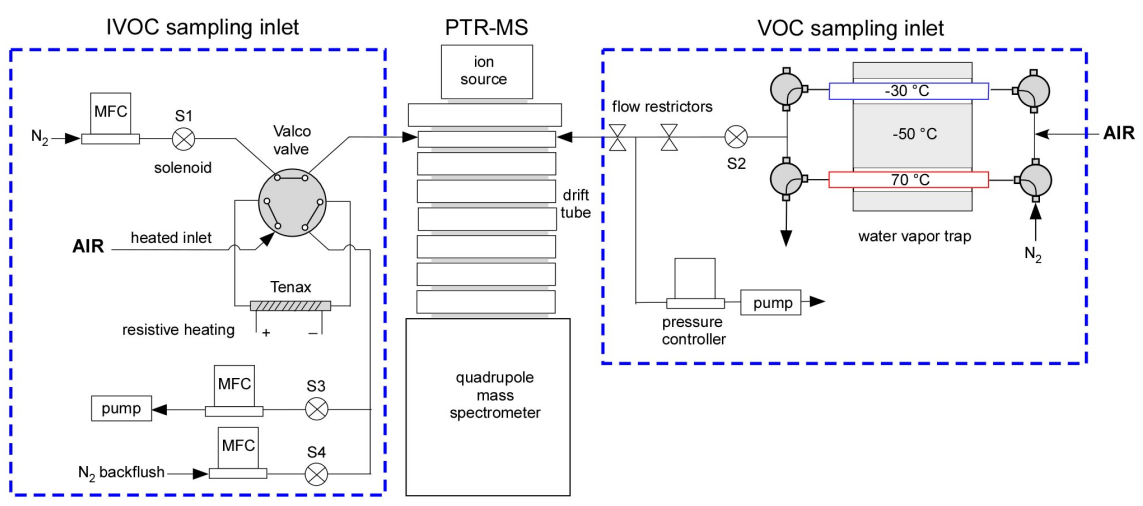

Fig. 1. Plumbing schematic showing thermal desorption sampler for IVOC compounds and VOC sampling system with water vapor trap.

operation of the drift tube at 80 Townsends (Td) to reduce fragmentation. Loss of $\mathrm{C}_{4}$-alkylbenzenes to the cold trap occurs at mixing ratios $<0.1 \mathrm{ppbv}$ (Jobson and McCoskey, 2010). In the diesel exhaust sampling experiments the $C_{4}$ to $\mathrm{C}_{6}$ alkylbenzene mixing ratios were $10 \mathrm{ppbv}$ or greater, and therefore losses to the cold trap are not expected to be significant but may result in lower measured abundance of $\mathrm{C}_{6}$ alkylbenzenes and compounds with lower vapor pressures. For the experiments and measurements described, the $80 \mathrm{Td}$ drift tube conditions were 2.08 mbar pressure, $70^{\circ} \mathrm{C}$ temperature, and drift tube voltage of $325 \mathrm{~V}$. Conditions for $120 \mathrm{Td}$ were the same except the voltage was increased to $485 \mathrm{~V}$.

The temperature of the Tenax trap was thermostated to control sampling, purging, back flush, and desorption temperatures. The sample collection temperature was $30^{\circ} \mathrm{C}$ and the desorption temperature as measured inside the trap was $230^{\circ} \mathrm{C}$. After desorption, the trap was kept at $230^{\circ} \mathrm{C}$ and back flushed with a $100 \mathrm{sccm} \mathrm{N} \mathrm{N}_{2}$ flow for $2 \mathrm{~min}$. The volume of air collected on the trap could be varied by controlling the sample collection time. Zero air was collected on the trap in the same manner as a sample and peak responses above the zero air signals were determined; no carryover effects from previous samples were observed in the zero air desorptions. Peak areas were integrated with custom analysis software (Wavemetrics IGOR Pro). The area under the desorption peak is proportional to the moles of analyte collected on the Tenax trap.

\subsection{Dynamic dilution system}

Compounds with low vapor pressures are typically not very stable as compressed gas standards. For calibrating the PTRMS response to IVOC species, a dynamic dilution system was used based on a low flow syringe pump (Harvard Apparatus). The syringe pump was used to continuously deliver low flow rates of a neat liquid into a dilution flow of air or nitrogen to produce stable and accurate test mixtures that could be analyzed for many hours of instrument testing. In these experiments the needle of a 0.5 to $50 \mu \mathrm{L}$ syringe pierced a septum on a heated stainless steel tee fitting where the liquid evaporated from the tip of the syringe under the flow of the diluent gas. The manifold tee where the liquids were injected was temperature controlled between 30 and $80^{\circ} \mathrm{C}$. Downstream of the manifold the tubing was temperature controlled to $80^{\circ} \mathrm{C}$. The PTR-MS sub-sampled from this flow. To determine the accuracy of the dynamic dilution system, test mixtures of toluene, p-xylene, and 1,3,5-trimethylbenzene were made, ranging from $1 \mathrm{ppbv}$ to $1 \mathrm{ppmv}$ by varying the infusion rate. These mixtures were sampled by the PTR-MS and the measured ion signal converted into a mixing ratio using calibrated response factors determined from a multicomponent VOC compressed gas standard containing these compounds (Scott-Marrin, accuracy $\pm 5 \%$ ). The measured molar mixing ratio was compared to that calculated from the infusion rate and molar flow of the diluent air. Measured mixing ratios agreed within $15 \%$ or better for mixing ratios $>10 \mathrm{ppbv}$, giving confidence that the system could reproducibly deliver reasonably accurate test mixtures for determining n-alkane sensitivities. For the n-alkane sensitivity tests, infusion rates ranging between 0.5 to $5 \mu \mathrm{Lh}^{-1}$ were diluted into $20 \mathrm{slpm}$ of dry nitrogen, yielding mixing ratios of approximately of $40 \mathrm{ppbv}$ or greater. It was observed that if the infusion rate was too low then evaporative loss from the needle was greater than the infusion rate. The lowest mixing ratios achievable were dependent on the compounds vapor pressure; lower vapor pressures allowed for lower syringe pump infusion rates. Gasoline and diesel fuel were also evaporated using this system to make test mixtures of the fuels for sampling by the PTR-MS.

\subsection{Engine exhaust sampling}

Diesel and gasoline engine exhaust were sampled from inhalation exposure chambers at the Lovelace Respiratory Research Institute (LRRI) in Albuquerque, NM. The diesel engine was a $5.5 \mathrm{~kW}$ Yanmar diesel electric generator and the gasoline engine a 1996 model General Motors 4.3-L V-6 mounted to a dynamometer. The emissions from these 
engines and facility description are described in more detail in McDonald et al. $(2004,2007,2011)$. The emissions output from these engines reflect older emission standards with the diesel generator simulating emissions from a medium duty diesel truck engine. Current US and European emission regulations for diesel truck engines are expected to significantly decrease diesel engine emissions of $\mathrm{NO}_{\mathrm{x}}$, particulate matter, and non-methane hydrocarbons over the next $20 \mathrm{yr}$ as the existing heavy duty diesel vehicle fleet is slowly replaced by newer vehicles with better emissions controls. The LRRI facility can blend diesel and gasoline engine exhaust in different proportions and thus provided an excellent opportunity to test the IVOC thermal desorption sampler. Over a series of tests, the engine load was varied and the exhaust diluted to different extents with clean, dry air. A portion of the diluted exhaust flow was diverted through a $1.5 \mathrm{~m}^{3}$ exposure chamber from which the PTR-MS sampled. The inlet for the PTRMS consisted of a heat-traced $\left(80^{\circ} \mathrm{C}\right)$ electropolished steel tubing (UHP Cardinal) protected by a $1.0 \mu \mathrm{m}$ Teflon particle filter that was replaced after each experiment.

\section{Results}

\section{1 n-alkane response}

The PTR-MS instrument measures organics $(R)$ via a proton transfer reaction with $\mathrm{H}_{3} \mathrm{O}^{+}$, producing a mass spectrum of an air sample that is ideally interpreted as an molecular weight $+1(M+1)$ mass spectrum:

$\mathrm{H}_{3} \mathrm{O}^{+}+R \rightarrow \mathrm{H}_{2} \mathrm{O}+\mathrm{RH}^{+}$

However, many dissociative proton transfer reactions are known to occur, complicating this interpretation. Reaction (R1) will be exothermic if the species $R$ has a greater proton affinity (PA) than $\mathrm{H}_{2} \mathrm{O}$ and exothermic proton transfer reactions occur near their collision rate limit (Bohme et al., 1979), making the PTR-MS sensitive to a wide variety of organic compounds. The proton affinity of $\mathrm{H}_{2} \mathrm{O}$ is $166.5 \pm 2 \mathrm{kcal} \mathrm{mol}^{-1}$ at $298 \mathrm{~K}$ (Lias et al., 1984) and the proton affinities for larger alkanes approach this value (Hunter and East, 2002). Spanel and Smith (1998) measured $\mathrm{H}_{3} \mathrm{O}^{+}$ reactions with alkanes using a selected ion flow tube. It was found that larger $\mathrm{n}$-alkanes can form an adduct with the hydronium ion:

$$
\mathrm{H}_{3} \mathrm{O}^{+}+\mathrm{C}_{10} \mathrm{H}_{22}+M \rightarrow \mathrm{H}^{+}\left(\mathrm{H}_{2} \mathrm{O}\right) \mathrm{C}_{10} \mathrm{H}_{22}+M
$$

The study also observed a ligand switching reaction that occurs in the presence of water vapor that catalyzed the formation of water clusters:

$$
\mathrm{H}^{+}\left(\mathrm{H}_{2} \mathrm{O}\right) \mathrm{C}_{10} \mathrm{H}_{22}+\mathrm{H}_{2} \mathrm{O} \rightarrow \mathrm{H}^{+}\left(\mathrm{H}_{2} \mathrm{O}\right)_{2}+\mathrm{C}_{10} \mathrm{H}_{22}
$$

In our studies with the PTR-MS instrument, adducts were observed during measurement of the $\mathrm{n}$-alkanes at $80 \mathrm{Td}$ but at very low abundance. There was also an increase in the $m / z 37$ ion abundance due to the water cluster $\mathrm{H}^{+}\left(\mathrm{H}_{2} \mathrm{O}\right)_{2}$, perhaps a result of Reaction (R3). The PTR-MS ion source also generates $\mathrm{O}_{2}^{+}$ions, which further confounds the interpretation of the PTR-MS mass spectrum as a simple $M+1$ mass spectrum. $\mathrm{O}_{2}^{+}$reacts rapidly with alkanes, causing extensive fragmentation (Spanel and Smith, 1998). To minimize the influence of $\mathrm{O}_{2}^{+}$, dry $\mathrm{N}_{2}$ was used as the diluent gas in the dynamic dilution system and in thermal desorption from the Tenax trap. Typically $\mathrm{O}_{2}^{+}$ion count rates were less than $0.1 \%$ of the $\mathrm{H}_{3} \mathrm{O}^{+}$count rate.

The n-alkanes undergo dissociative proton transfer reactions in the PTR-MS (Jobson et al., 2005), producing fragmentation patterns similar to electron impact ionization. Figure 2 shows the fragmentation pattern for dodecane as an example of the typical pattern observed for n-alkanes. The $\mathrm{C}_{8}-\mathrm{C}_{16} \mathrm{n}$-alkanes produced a significant response and their spectra displayed similar features, yielding a pattern of fragment ions with the formula $\mathrm{C}_{n} \mathrm{H}_{2 n+1}$ for $n \geq 3$. For heptane and smaller $\mathrm{n}$-alkanes there was little response and these species appear to be unreactive with $\mathrm{H}_{3} \mathrm{O}^{+}$at these drift tube conditions. The n-alkane fragmentation pattern was a function of the Townsend number. At lower Townsend numbers there was less fragmentation into lighter ions. At $80 \mathrm{Td}$ there was essentially no fragmentation to $m / z 41$ and 43 while at $120 \mathrm{Td}$ these were two of the most abundant fragment ions. At 80 Td the $M-1$ ion was much more abundant. Preliminary tests have shown that branched and iso-alkanes display similar fragmentation patterns as n-alkanes but there is often a more significant $M-1$ ion.

The benefit of operating at lower $\mathrm{Td}$ is that the n-alkane ion signal occurs at larger ion masses, allowing for better distinction between IVOC and VOC species. The ions $m / z 41$, 43 and 57 are common fragment ions from a wide range of compounds and are typically the most abundant ion signals in PTR-MS analysis of urban air. At $80 \mathrm{Td}$, approximately $70 \%$ of the ion signal occurs at $m / z 57,71$, and 85 for the $\mathrm{C}_{9}$ to $\mathrm{C}_{16} \mathrm{n}$-alkanes. There would be significant interference from VOC compounds found in urban air for $m / z 57$ (from butenes) and $m / z 71$ (from pentenes, methacrolein, methyl vinyl ketone). To use these ions to monitor for IVOC alkanes required a discrimination strategy to prevent interfering VOCs from being measured during thermal desorption. Our approach, described in more detail below, was to purge the Tenax trap at an elevated temperature after sample collection to remove VOCs, then desorb the trap at higher temperatures to measure the heavier organics that remained.

The PTR-MS instrument's sensitivity to alkanes was determined by preparing known n-alkane and toluene mixtures using the dynamic dilution system. The sum of the $\mathrm{C}_{n} \mathrm{H}_{2 n+1}$ ions response $(m / z 43,57,71,85, \ldots)$ for each n-alkane was divided by the reagent ion signal in $\mathrm{MHz}$ and the $\mathrm{n}$ alkane mixing ratio to get the normalized sensitivity in units of $\mathrm{Hz} \mathrm{ppbv}^{-1}$ per $\mathrm{MHz} \mathrm{H}_{3} \mathrm{O}^{+}$(ncps). The alkane species of interest was co-injected with toluene to ensure the syringe 


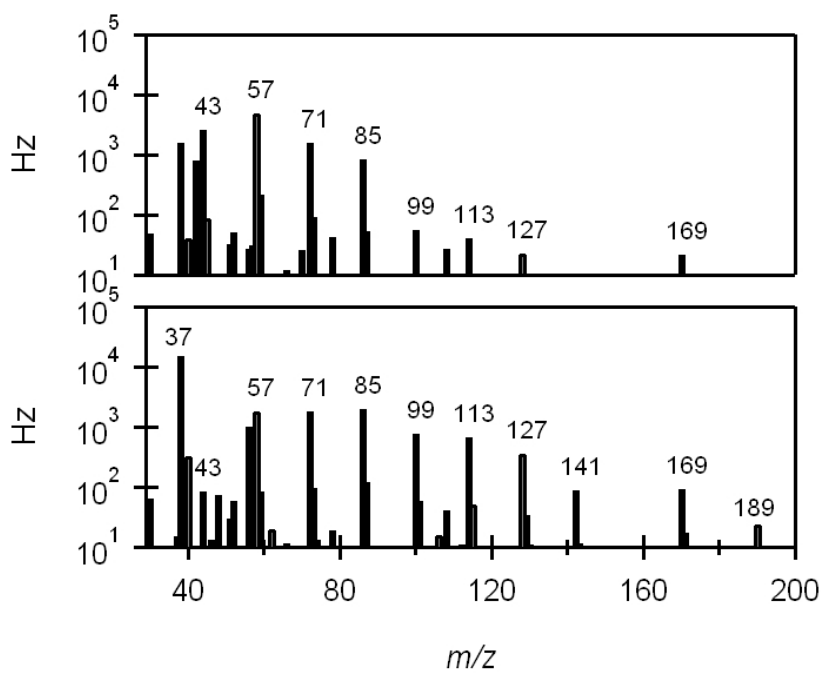

Fig. 2. PTR-MS raw mass spectrum of dodecane $\left(\mathrm{C}_{12} \mathrm{H}_{26}\right)$ at $120 \mathrm{Td}$ (upper panel) and $80 \mathrm{Td}$ (lower panel) drift tube conditions. A clear pattern of $\mathrm{C}_{n} \mathrm{H}_{2 n-1}$ ion fragments is evident. At $80 \mathrm{Td}$ the $M-1$ ion $(m / z 169)$ is more intense. The $m / z 189$ ion is attributed to the $M \cdot \mathrm{H}_{3} \mathrm{O}^{+}$cluster.

pump was operating correctly, since an expected signal for toluene can be calculated from a known response to external gas phase standards. The n-alkane sensitivity is shown in Fig. 3. The response curve displays a dependence on the drift conditions. The PTR-MS was insensitive to alkanes with carbon numbers $<\mathrm{C}_{8}$. The increase in sensitivity for alkanes $>C_{7}$ is consistent with the rate constant measurements of Arnold et al. (1998), which are also shown in the figure. Quantum mechanical calculations of alkane C-C bond proton affinities reveal that the more central bonds of the molecule have the largest proton affinities and for larger alkanes approach that of water at $166.5 \mathrm{kcal} \mathrm{mol}^{-1}$ (Hunter and East, 2002). The $\mathrm{H}_{3} \mathrm{O}^{+}+$n-alkane reaction appears to be endothermic and explains why the n-alkane sensitivity is significantly lower than that of toluene. Using the summed ion signal for all $\mathrm{C}_{n} \mathrm{H}_{2 n+1}(n \geq 3)$ fragment ions, the normalized sensitivity for dodecane at $120 \mathrm{Td}$ was $2.4 \mathrm{ncps}$, compared to $9 \mathrm{ncps}$ for toluene. The PA of n-alkanes appears to plateau for larger alkanes and the $120 \mathrm{Td}$ sensitivity curve suggests a sensitivity plateau as well for $\mathrm{n}$-alkanes $>\mathrm{C}_{14}$. At the $80 \mathrm{Td}$ condition, normalized sensitivities should increase due to the $150 \%$ increase in reaction time. The expected sensitivity increase was observed for toluene but not for the $\mathrm{n}$-alkanes. The similarity in sensitivity for $\mathrm{C}_{8}-\mathrm{C}_{11} \mathrm{n}$-alkanes at the two drift conditions may be due to a decrease in $\mathrm{H}_{3} \mathrm{O}^{+}$reaction rate constants at $80 \mathrm{Td}$, offsetting the increase in reaction time. Another factor is ion transmission efficiency. At $120 \mathrm{Td}$ the $\mathrm{n}$-alkane sensitivity was primarily determined by the ion signal at $m / z 41$, 43 and 57 while at $80 \mathrm{Td}$ the sensitivity was determined by broader range of heavier ion masses, as illustrated in Fig. 2, with most of the ion signal $(>50 \%)$ at $m / z 57,71,85$. At

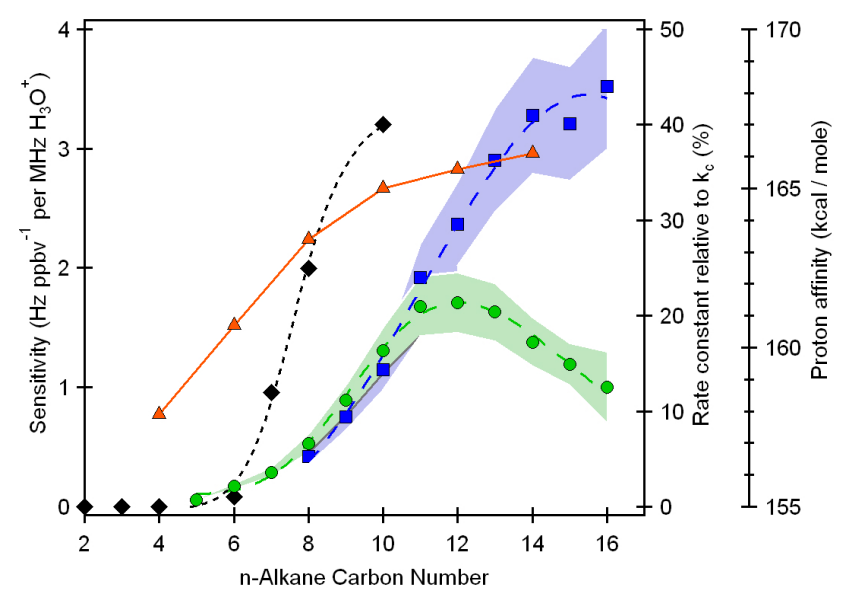

Fig. 3. n-alkane sensitivity (left axis) for $120 \mathrm{Td}$ (blue squares) and $80 \mathrm{Td}$ (green circles) with shading representing the $15 \%$ estimated accuracy of the test mixture preparation. Measured $\mathrm{H}_{3} \mathrm{O}^{+}+\mathrm{n}$ alkane rate coefficients (black diamonds) by Arnold et al. (1998), expressed as a percentage of the collision rate limit (right axis), are shown for trend comparison along with proton affinity (red triangles) determined by Hunter and East (2002).

$80 \mathrm{Td}$ the dodecane sensitivity was $1.7 \mathrm{ncps}$ and the sensitivity of the $\mathrm{C}_{14}-\mathrm{C}_{16} \mathrm{n}$-alkanes appeared to display a decreasing trend with increasing chain length. The decreasing trend was in part due to lower ion transmission efficiency for the heavier ions produced by these alkanes, but the large difference between the $120 \mathrm{Td}$ and $80 \mathrm{Td}$ sensitivities for these alkanes could not be readily explained.

\subsection{Diesel and gasoline fuel mass spectra}

To better understand what constituents of vehicle fuels and exhausts the PTR-MS may respond to, gasoline and diesel fuel no. 2 used in the engine exhaust studies were measured by evaporating $5 \mu \mathrm{L} \mathrm{h}^{-1}$ of whole fuel into $20 \mathrm{slpm}$ of dry nitrogen at an injection manifold temperature of $60^{\circ} \mathrm{C}$. The PTR-MS sampled directly from this flow, bypassing the thermal desorption sampler and water trap. Gasoline is mostly comprised of hydrocarbons in the $\mathrm{C}_{4}$ to $\mathrm{C}_{10}$ range while diesel fuel consists of $\mathrm{C}_{8}$ to $\mathrm{C}_{25}$ hydrocarbons (Han et al., 2008; Schauer et al., 1999; Lough et al., 2005; Gentner et al., 2012; Wang et al., 2005). Exhaust is a more complex mixture that contains fuel hydrocarbons plus oxygenated compounds such as aldehydes and ketones, and other hydrocarbons such as alkenes, acetylene, and pyrogenic compounds (Schauer et al., 1999, 2002). Both fuels were sampled at 80 and $120 \mathrm{Td}$ drift conditions and the resulting mass spectra are shown in Fig. 4. Distinct ion group patterns were observed in both fuel types. These groups can be related to different organic compound classes and are identified by color in the figure. The gasoline contained $10 \%$ ethanol by volume, producing an ethanol $M+1$ ion at $m / z 47$ and an ethanol water cluster ion at $m / z 65$ in the $80 \mathrm{Td}$ gasoline mass spectra. The relative 

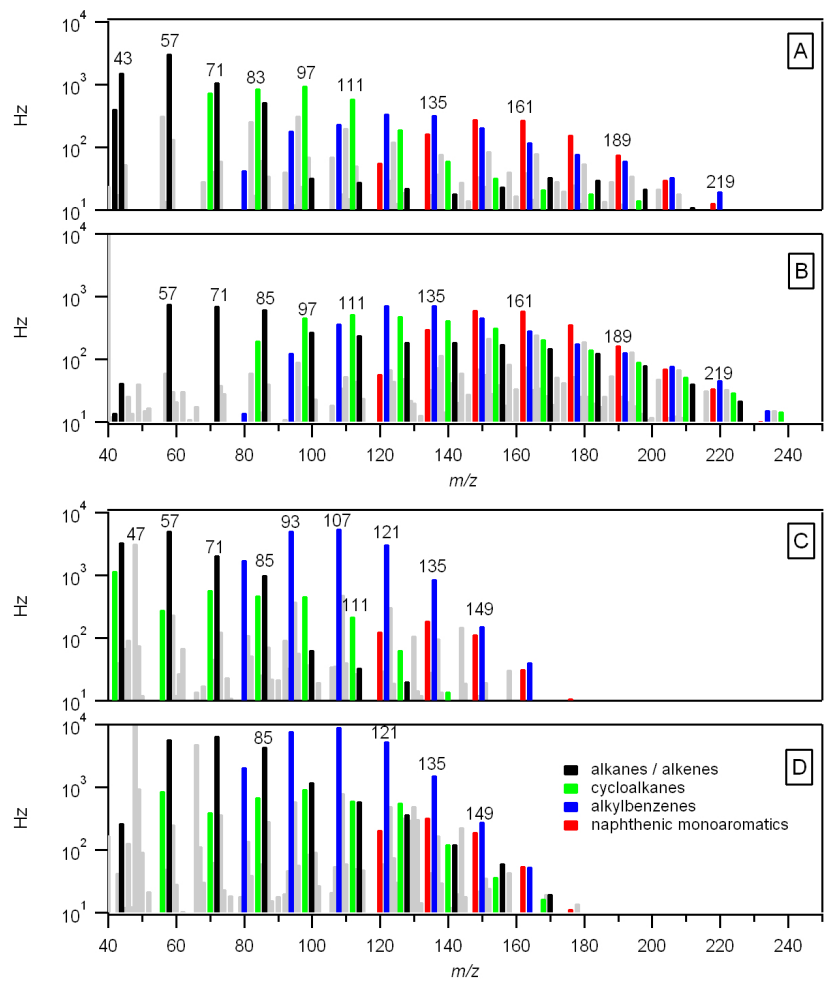

Fig. 4. PTR-MS mass spectrum of diesel fuel no. 2 at $120 \mathrm{Td}$ (A) and $80 \mathrm{Td}(\mathbf{B})$ and gasoline at $120 \mathrm{Td}(\mathbf{C})$ and $80 \mathrm{Td}(\mathbf{D})$. Ion signal has been color-coded to identify organic compound classes.

intensity of the ion signal gives a qualitative indication of the relative molar abundance of the different constituents; the ion intensities were not corrected for differences in ion transmission efficiency and compound sensitivity. The PTR-MS mass spectrum for gasoline ends around $m / z 180$ while significant ion signal in the diesel fuel mass spectrum was still observed to $m / z 240$, indicating $\mathrm{C}_{18}$ compounds, and represents the apparent upper limit of our observable range. Larger molecular weight compounds were likely not transmitted efficiently through the sampling tubing. There were more pronounced differences in the $120 \mathrm{Td}$ and $80 \mathrm{Td}$ mass spectra of diesel fuel than gasoline, with significant shifts to higher $m / z$ ions for the $\mathrm{C}_{n} \mathrm{H}_{2 n+1}$ and $\mathrm{C}_{n} \mathrm{H}_{2 n-1}$ ion groups in diesel fuel, suggesting significant fragmentation of hydrocarbons.

Comprehensive analysis of diesel fuel has shown that alkenes are not present in the fuel; it is primarily composed of alkanes ( $30 \%$ by mass), cycloalkanes ( $20 \%$ ), and monoaromatic compounds (18\%) (Venduevre et al., 2005; Gentner et al., 2012). The series of ions in diesel fuel corresponding to masses $\mathrm{C}_{n} \mathrm{H}_{2 n+1}$ for $n \geq 3$, listed in Table 1, were therefore attributed to alkanes; these masses are shown as black bars in Fig. 4. Alkanes are also a significant component of gasoline but the PTR-MS is relatively insensitive to alkanes with less than 8 carbons. For summer blends of gasoline, alkanes with 8 or more carbon atoms comprise about $30 \%$ of the total alkane composition on a molar basis (Lough et al., 2005; Gentner et al., 2012) and these compounds would produce a signal at the $\mathrm{C}_{n} \mathrm{H}_{2 n+1}$ ion masses. Contributions to signal at $m / z 57,71$, and 85 could also be due to $\mathrm{C}_{4}-\mathrm{C}_{6}$ alkenes. These compounds comprise a much smaller molar fraction of whole gasoline, on the order of $4 \%$ (Lough et al., 2005; Gentner et al., 2012), but the PTR-MS is much more sensitive to these compounds than alkanes. The $\mathrm{C}_{n} \mathrm{H}_{2 n+1}$ ion signal likely reflects contributions from alkanes and alkenes. In contrast to diesel fuel, the mass spectrum of gasoline was thus dominated by alkylbenzene constituents, in particular toluene $(\mathrm{m} / \mathrm{z} 93)$ and the xylene isomers $(\mathrm{m} / \mathrm{z}$ 107), owing to their greater molar fractional abundance in gasoline and the instruments low sensitivity to $\mathrm{C}_{4}-\mathrm{C}_{10}$ alkanes.

The prominent group of ions with mass formula $\mathrm{C}_{n} \mathrm{H}_{2 n-1}$ $(n \geq 5)$ was attributed to alkyl-substituted cycloalkanes, as listed in Table 1 and indicated as green bars in Fig. 4. Gentner et al. (2012) have reported the presence of $C_{7}$ to $C_{25}$ cycloalkane compounds in diesel fuel, with mass fractional contribution by carbon number ranging from $0.15 \%$ for $\mathrm{C}_{7}$ compounds to $2.2 \%$ for $\mathrm{C}_{10}, \mathrm{C}_{11}$, and $\mathrm{C}_{12}$ compounds, diminishing to $1.1 \%$ for $\mathrm{C}_{18}$ compounds. As noted in Table 1 , this ion group comprised $17.7 \%$ of the total ion signal for diesel fuel at $80 \mathrm{Td}$ and $5.4 \%$ for gasoline, with ions $\mathrm{m} / z 69$, $83,97,111$ and 125 the most abundant. Laboratory tests confirmed that cyclopentanes and cyclohexanes yield these ions at 80 and $120 \mathrm{Td}$ drift tube conditions. At $80 \mathrm{Td}$ these compounds yield an $M-1$ ion as the major fragment ion. Exceptions were cyclopentane, cyclohexane, and methylcyclopentane, where $M+1$ ions were observed as the dominant ion. These compounds are removed during the Tenax trap purge and would not interfere with thermal desorption analysis of alkanes. Methylcyclohexane, dimethylcyclohexane isomers, and trimethylcyclohexane isomers yielded $M-1$ ions at greater than $95 \%$ yield. At $120 \mathrm{Td}$ the $M-1$ ion was produced but at significantly lower yields and many more fragment ions were observed including $m / z 69$. Cyclohexane has a proton affinity less than that of $\mathrm{H}_{2} \mathrm{O}$ but our tests suggest the PTR-MS was more sensitive to alkyl-substituted cyclohexanes, implying they have greater proton affinity. For diesel fuel at $80 \mathrm{Td}$, the ion signal for this group was more intense than the corresponding alkane ion at a similar mass. The ion intensity for this group was relatively uniform from $m / z 97$ to $m / z .153$, and then decreased rapidly to the heaviest ion measured at $m / z 237$, corresponding to a $\mathrm{C}_{17}$ compound.

The alkylbenzene compounds identified as blue bars in Fig. 4 and listed in Table 1 were also prominent in diesel fuel mass spectra, comprising $20 \%$ of the total ion signal at $80 \mathrm{Td}$. Ion signal for these species ranges from $m / z 79$ (benzene) to $m / z 233$, indicating $C_{18}$ compounds. Most of the ion intensity was at $m / z 121$ and 135 , corresponding to alkylbenzene compounds with 9 and 10 carbon atoms, respectively; these are respectively identified as $\mathrm{C}_{3}$-alkylbenzenes and $\mathrm{C}_{4}$ alkylbenzenes to indicate the number of carbon atoms in the alkyl groups attached to the benzene ring. The Gentner et 
Table 1. Percent of total ion signal for the different groups in diesel and gasoline fuels.

\begin{tabular}{|c|c|c|c|c|c|c|c|}
\hline Compound group & $\begin{array}{l}\text { Mass } \\
\text { formula }\end{array}$ & $\begin{array}{l}\text { Base } \\
\text { ion }\end{array}$ & Major $m / z$ & $\begin{array}{l}\text { Diesel } \\
\mathrm{Td}=120\end{array}$ & $\begin{array}{l}\text { Diesel } \\
\mathrm{Td}=80\end{array}$ & $\begin{array}{l}\text { Gasoline } \\
\mathrm{Td}=120\end{array}$ & $\begin{array}{l}\text { Gasoline } \\
\mathrm{Td}=80\end{array}$ \\
\hline alkanes + alkenes & $\mathrm{C}_{n} \mathrm{H}_{2 n+1}$ & & $\begin{array}{l}43,57,71,85, \\
99,113,127, \\
141,155,169\end{array}$ & $43.30 \%$ & $23.20 \%$ & $36.80 \%$ & $31.10 \%$ \\
\hline cycloalkanes & $\mathrm{C}_{n} \mathrm{H}_{2 n-1}$ & $M-1$ & $\begin{array}{l}69,83,97, \\
111,125,139, \\
153,167,181\end{array}$ & $17.10 \%$ & $17.70 \%$ & $5.30 \%$ & $5.40 \%$ \\
\hline bicylcloalkanes & $\mathrm{C}_{n+5} \mathrm{H}_{2 n+7}$ & $M-1$ & $\begin{array}{l}123,137,151, \\
165,179,193\end{array}$ & $8.20 \%$ & $8.20 \%$ & $0.60 \%$ & $0.50 \%$ \\
\hline alkylbenzenes & $\mathrm{C}_{n+6} \mathrm{H}_{2 n+7}$ & $M+1$ & $\begin{array}{l}79,93,107, \\
121,135,149, \\
163,177,191\end{array}$ & $10.50 \%$ & $20.10 \%$ & $47.90 \%$ & $42.20 \%$ \\
\hline naphthenic monoaromatics & $\mathrm{C}_{n+9} \mathrm{H}_{2 n+11}$ & $M+1$ & $\begin{array}{l}119,133,147, \\
161,175,189, \\
203\end{array}$ & $7.40 \%$ & $14.30 \%$ & $1.70 \%$ & $1.40 \%$ \\
\hline dihydro-naphthalenes & $\mathrm{C}_{n+10} \mathrm{H}_{2 n+11}$ & $M+1$ & $\begin{array}{l}131,145,159, \\
173,187,201\end{array}$ & $0.80 \%$ & $1.70 \%$ & $0.10 \%$ & $0.10 \%$ \\
\hline naphthalenes & $\mathrm{C}_{n+10} \mathrm{H}_{2 n+9}$ & $M+1$ & $\begin{array}{l}129,143,157, \\
171,185\end{array}$ & $0.80 \%$ & $1.70 \%$ & $0.90 \%$ & $1.30 \%$ \\
\hline Sum of ion signal & & & & $88 \%$ & $87 \%$ & $93 \%$ & $82 \%$ \\
\hline
\end{tabular}

al. (2012) analysis of diesel fuel reports the most abundant aromatics by carbon number are $\mathrm{C}_{10}$ compounds at $2.4 \%$ by weight carbon, decreasing gradually to $0.8 \%$ abundance for $\mathrm{C}_{18}$ compounds, the limit of our observable range, down to $0.2 \%$ for $\mathrm{C}_{25}$ compounds. Examination of the alkylbenzene ion abundance relative to $\mathrm{m} / \mathrm{z} 149$ showed that fragmentation of higher molecular weight aromatics was occurring, as evidenced by much larger abundance of $m / z 79,93$, and 107 ions at $120 \mathrm{Td}$ than at $80 \mathrm{Td}$. At $120 \mathrm{Td} \mathrm{m} / z 79$ was a factor of 7 more abundant, $m / z, 93$ was 3 times more abundant, and $m / z 107$ was 1.4 times more abundant. The relative abundance of $m / z 135$ and ions larger than $m / z 149$ were very similar for the two drift conditions, within $5 \%$, with the exception of $m / z 233$, which was a factor of 2 higher at $80 \mathrm{Td}$. Tests performed on fragmentation patterns for a suite of methyl, ethyl, n-propyl, i-propyl, and n-pentyl alkyl-substituted benzene compounds have shown that few compounds fragment at the $80 \mathrm{Td}$ drift field energies, exceptions being compounds with isopropyl groups. For example, $10 \%$ of p-cymene fragments to produce at ion at $m / z 93$. At $120 \mathrm{Td}$ a greater degree of fragmentation was observed and $m / z 79$ and $m / z 93$ were common fragment ions. The occurrence of an ion at $m / z 79$ (benzene) in diesel fuel may be entirely due to fragmentation of larger alkylbenzene compounds. It was also observed that some aromatic compounds (i.e., n-pentylbenzene, 1,3-diisopropylbenzene, 2,2-dimethyl-1-propylbenzene) yielded significant fragmentation to $m / z 43$. Operating the PTR-MS at lower Td values would provide a higher fidelity measure of alkylbenzene mass distribution in diesel fuel given the prevalence of higher molecular weight alkylbenzene compounds. The alkylbenzene compounds are isobaric with the tricycloalkane compounds identified as being present in diesel fuel by Gentner et al. (2012), though ranging from a factor of 2 less abundant for $\mathrm{C}_{18}$ to a factor of 20 less abundant for $\mathrm{C}_{10}$ compounds.

An ion group with a formula $\mathrm{C}_{n+9} \mathrm{H}_{2 n+11}(n \geq 0)$ makes up $14 \%$ of the total diesel fuel ion signal at $80 \mathrm{Td}$ but less than $2 \%$ of the gasoline ion signal, as shown as red bars in Fig. 4 and listed in Table 1. If the ion signal pattern can be interpreted as an $\mathrm{M}+1$ mass spectrum then this group could be a series of alkyl-substituted indane $\left(\mathrm{C}_{9} \mathrm{H}_{10}\right)$ and 1,2,3,4tetrahydronaphthalene (tetralin, $\mathrm{C}_{10} \mathrm{H}_{12}$ ) compounds. Laboratory tests demonstrated that at $80 \mathrm{Td}$ indane and tetralin yield $M+1$ ions at $m / z 119$ and 133 , respectively, with no fragmentation. Such compounds are comprised of a benzene ring fused to a cycloalkane structure. The presence of such naphthenic monoaromatics has been reported in diesel fuel (Vendeuvre et al., 2005, 2007). Ions at $\mathrm{m} / z 91$ and 105 may also belong to this series, possessing a 3- or 4-member alkyl ring structure, respectively. The ring structure is isobaric with an alkene functional group but there are few reports of alkenes being prominent in diesel fuel.

About $6 \%$ of the diesel fuel ion signal was comprised of an ion group with mass formula $\mathrm{C}_{n+5} \mathrm{H}_{2 n+7}(n \geq 0)$. This group contributes less than $1 \%$ of the ion signal in the gasoline mass spectrum. These compounds may be bicycloalkanes $\left(\mathrm{C}_{8} \mathrm{H}_{14}, \mathrm{C}_{9} \mathrm{H}_{16}, \mathrm{C}_{10} \mathrm{H}_{18}\right)$ and related alkylsubstituted compounds. Bicycloalkanes with 10 or more carbon atoms have been identified as a significant constituent in diesel fuel (Gentner et al., 2012). Laboratory experiments 
at $80 \mathrm{Td}$ demonstrated that decahydronaphthalene $\left(\mathrm{C}_{10} \mathrm{H}_{18}\right)$ yields an $M-1$ ion at $m / z 137$. At $120 \mathrm{Td}$ there was significant fragmentation to $m / z 67,81$ and 95 , accounting for 1,50 , and $11 \%$ of the signal, respectively, with $38 \%$ of the response at $m / z$ 137. Naphthalene and alkyl-substituted naphthalenes with mass formula $\mathrm{C}_{n+10} \mathrm{H}_{2 n+9}(n \geq 0)$ and dihydronapthalenes, $\mathrm{C}_{n+10} \mathrm{H}_{2 n+11}$, both yield $M+1$ ions at $80 \mathrm{Td}$, as demonstrated in laboratory tests. These compounds comprise a small fraction of the fuel ion signal. Their masses and total group ion signal abundance are listed in Table 1.

The relative contributions from each of these compound classes can be seen in Fig. 5, which shows the PTR-MS mass spectrum for diesel fuel measured at $80 \mathrm{Td}$ over the $\mathrm{C}_{12}$ to $\mathrm{C}_{14}$ carbon number range. Sensitivities for unsaturated compounds will likely be similar and thus the relative ion abundance reflects relative molar composition for a particular carbon number. The figure shows a similar pattern of group abundance for the different carbon number ranges, arranged by mass from the least saturated compounds (naphthalenes) to the most saturated compounds (alkanes). The identifications are tentative and need to be verified by more specific analytical techniques, but suggest that soft ionization by $\mathrm{H}_{3} \mathrm{O}^{+}$may be useful for characterizing the compound group composition of diesel fuel. In this analysis the naphthenic monoaromatics, possibly alkyl-substituted tetralin compounds, are more abundant than the equivalent carbon number alkylbenzenes in the $\mathrm{C}_{12}$ to $\mathrm{C}_{14}$ compound range.

\subsection{Diesel and gasoline exhaust mass spectra}

Representative mass spectra of diesel and gasoline engine exhaust are shown in Fig. 6 with ions grouped and color-coded by compound classes, as was done for the fuel. The data were collected at $80 \mathrm{Td}$ in VOC mode using a $-30^{\circ} \mathrm{C}$ dehumidifier to remove water vapor and, to some extent, depending on exhaust concentrations, lower volatility organics. Shown are ions measured in selective ion measuring mode of the PTR-MS and include major ions from the compound groups identified in diesel fuel plus ions attributed to oxygenated species known to be emitted in exhaust, such as formaldehyde $(m / z 31)$, acetaldehyde $(m / z 45), 2$-propenal $(m / z 57)$, acetone + propanal + glyoxal $(\mathrm{m} / z 59)$, and 2-butenal and methacrolein $(m / z 71)$. Schauer et al. (1999) reported unsaturated carbonyl emission rates in diesel exhaust to be much greater than the corresponding light alkenes, and thus ion signal at $m / z 57$ and 71 in the diesel exhaust mass spectrum likely has a dominant contribution from these compounds. Similarly, benzaldehyde is isobaric with the $\mathrm{C}_{2}$-alkylbenzene isomers and the $m / z 107$ ion signal in diesel exhaust likely has significant contributions from this aldehyde. In gasoline engine exhaust these aldehydes are less abundant than the isobaric alkene or aromatic compound (Schauer et al., 2002). The diesel engine was operated under a low engine load $(1.5 \mathrm{~kW})$, the gasoline engine was operated under a typical

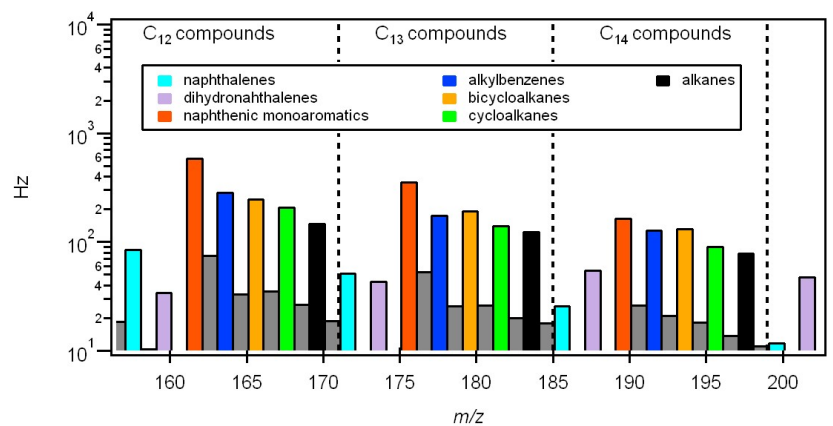

Fig. 5. Examination of the $\mathrm{C}_{12}-\mathrm{C}_{14}$ compound range ion signal pattern for diesel fuel. Peaks have been tentatively identified as belonging to 1 of 7 compound groups that differ by the degree of unsaturation, ranging from naphthalenes to alkanes.

engine load (1100 rpm) and both exhausts were diluted with similar flows of dry air. For a similar level of dilution, gasoline exhaust displayed much higher concentrations of VOCs. For both engine types the major organic compounds in exhaust have been reported to be aldehydes, light alkenes and alkanes, and alkylbenzenes (Hoekman, 1992; Schauer et al., 1999, 2002; Schmitz et al., 2000; Smith et al., 2002; Jobson et al., 2005). The exhaust composition is thus significantly different than the fuel composition, particularly for diesel exhaust, where a large fraction of the mass emission rate is comprised of low molecular weight compounds not present in the fuel. This compositional change is reflected in the PTR-MS mass spectrum with prominent peaks associated with aldehydes and ketones $(m / z 31,45,59,73)$, light alkenes and unsaturated aldehydes $(\mathrm{m} / \mathrm{z} 43,57,71)$, and alkylbenzenes $(m / z 79,93,107,121,135)$. The PTRMS mass spectrums of the diesel and gasoline engine exhaust thus appear quite similar. We cannot exclude the possibility that line losses of heavier organic compounds may occur in the ducting of the exhaust to the chambers and in the instrument sampling lines, making the exhaust appear more similar than in actuality. Table 2 compares the percentage of ion signal found for selected ions within the different compound groups for the fuel and exhaust. For PTR-MS measurements of long chain alkanes and other IVOC species associated with engine exhaust in urban air, it will be necessary to both discriminate against the very abundant light alkenes that produce interfering ions for the measurement of IVOC alkanes and to preconcentrate the air sample to improve detection of the much lower abundant IVOC range species. For example, the ion signal for IVOC alkylbenzenes with carbon numbers of 10 or greater is about 2 orders of magnitude less than xylenes at $m / z 107$. This need motivates thermal desorption sampling that can both discriminate against volatile alkenes and preconcentrate IVOC compounds. 
Table 2. Comparison of fuel and exhaust composition at $80 \mathrm{Td}$.

\begin{tabular}{|c|c|c|c|c|c|c|}
\hline Group & Formula & Measured $m / z$ & $\begin{array}{r}\text { Diesel } \\
\text { fuel }\end{array}$ & $\begin{array}{r}\text { Diesel } \\
\text { exhaust }\end{array}$ & $\begin{array}{r}\text { Gasoline } \\
\text { fuel }\end{array}$ & $\begin{array}{r}\text { Gasoline } \\
\text { exhaust }\end{array}$ \\
\hline oxygenated & & $31,33,45,47,59$ & $19.7 \%$ & $50.3 \%$ & $45.1 \%$ & $51.1 \%$ \\
\hline $\begin{array}{l}\text { alkanes + alkenes } \\
\text { + unsaturated aldehydes }\end{array}$ & $\mathrm{C}_{n} \mathrm{H}_{2 n+1}$ & $\begin{array}{l}43,57,71,85,99 \\
113,127\end{array}$ & $20.3 \%$ & $19.4 \%$ & $20.6 \%$ & $16.4 \%$ \\
\hline cycloalkanes & $\mathrm{C}_{n} \mathrm{H}_{2 n-1}$ & $69,83,97,111,125,139$ & $15.3 \%$ & $4.3 \%$ & $3.6 \%$ & $3.3 \%$ \\
\hline alkylbenzenes & $\mathrm{C}_{n+6} \mathrm{H}_{2 n+7}$ & $\begin{array}{l}79,93,107,121,135 \\
149,163,177,191\end{array}$ & $21.9 \%$ & $22.3 \%$ & $28.6 \%$ & $26.6 \%$ \\
\hline bicycloalkanes & $\mathrm{C}_{n+5} \mathrm{H}_{2 n+7}$ & $\begin{array}{l}81,95,109,123,137 \\
151,165\end{array}$ & $6.1 \%$ & $2.5 \%$ & $0.3 \%$ & $1.3 \%$ \\
\hline naphthenic monoaromatics & $\mathrm{C}_{n+9} \mathrm{H}_{2 n+11}$ & $\begin{array}{l}119,133,147,161, \\
175,189\end{array}$ & $15.1 \%$ & $0.9 \%$ & $0.9 \%$ & $1.0 \%$ \\
\hline naphthalenes & $\mathrm{C}_{n+10} \mathrm{H}_{2 n+9}$ & $129,143,157,171$ & $1.6 \%$ & $0.3 \%$ & $0.8 \%$ & $0.3 \%$ \\
\hline
\end{tabular}

\subsection{Thermal desorption sampling}

Figure 7 shows an example of the thermal desorption peak from the trap, as described in Sect. 2.1. Shown is a time series of the 1,3,5-trimethylbenzene ion signal $(\mathrm{m} / \mathrm{z} 121)$ from a calibration gas test mixture prepared in humidified zero air. The test mixture was measured in VOC mode, passing through the $-30^{\circ} \mathrm{C}$ water trap, while a $257 \mathrm{cc}$ air sample was simultaneously being collected on the Tenax trap over a sampling period of $6 \mathrm{~min}$, as indicated by the shaded area under the trap flow rate in the figure. After sample collection, the trap was purged with dry $\mathrm{N}_{2}$ for $4.5 \mathrm{~min}$ to remove traces of air, then the gas sampling valve was rotated to connect the trap to the drift tube. After $30 \mathrm{~s}$ of settling time the trap was heated to $230^{\circ} \mathrm{C}$ in $65 \mathrm{~s}$ under a $25 \mathrm{sccm}$ carrier $\mathrm{N}_{2}$ flow. To demonstrate the trapping efficiency and equivalent sensitivity for the 2 modes, the area under the desorption peak (A2) can be shown to be equal to the area under the VOC trace (A1), accounting for the differences in air volume sampled. The product of IVOC sample collection time in seconds multiplied by the $m / z 121$ normalized count rates in VOC mode yields area A1 of 50000 counts. The air flow through the drift tube is $25 \mathrm{sccm}$, corresponding to a $150 \mathrm{~cm}^{3}$ volume of air sampled through the drift over the IVOC sample collection time. The VOC air sample volume is thus $58 \%$ the size of the IVOC air sample volume. Multiplying the IVOC area A2 of 88420 counts by the ratio of sample volumes yields an equivalent area of 51600 counts, only $3 \%$ larger than area A1. The peak area A2 is determined from the start of the desorption heating time to when the ion signal reaches the background count rate. As in VOC mode, humid zero air is collected on the Tenax trap in the same manner as an air sample and desorbed to determine background area counts.

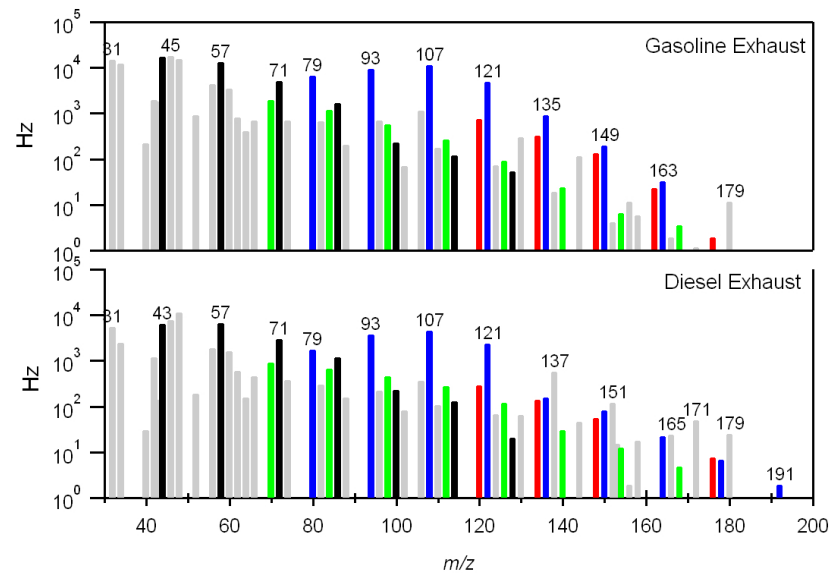

Fig. 6. PTR-MS mass spectrum of gasoline exhaust (top) and diesel exhaust (bottom) at $80 \mathrm{Td}$. Ion signal has been color-coded to assign ions to common fragmentation patterns that identify common organic compound classes: alkene and alkane fragment ions (black), alkylbenzenes (blue), cycloalkane fragment ions (green) and naphthenic monoaromatics (red). The abundance of unsaturated aldehydes in diesel exhaust likely dominates ion signal at $m / z 57$ and 71 .

In VOC mode the molar mixing ratios for some compound $X_{i}$ in $\mathrm{nmol} \mathrm{mol}^{-1}$ (ppbv) are determined from the measured ion count rates by

VOC : $X_{i}=\frac{S_{(i)}-\operatorname{bkg}_{(i)}}{\mathrm{ncps}_{(i)} \times \mathrm{MHzH}_{3} \mathrm{O}^{+}}$,

where $S$ and bkg are respectively the measured and background ion count rates $(\mathrm{Hz})$, and ncps is the normalized sensitivity for the compound in units of $\mathrm{Hz} \mathrm{ppbv}^{-1}$ per $\mathrm{MHz}$ $\mathrm{H}_{3} \mathrm{O}^{+}$. For IVOC mode a similar relationship holds to convert peak areas to molar mixing ratios but must also account 


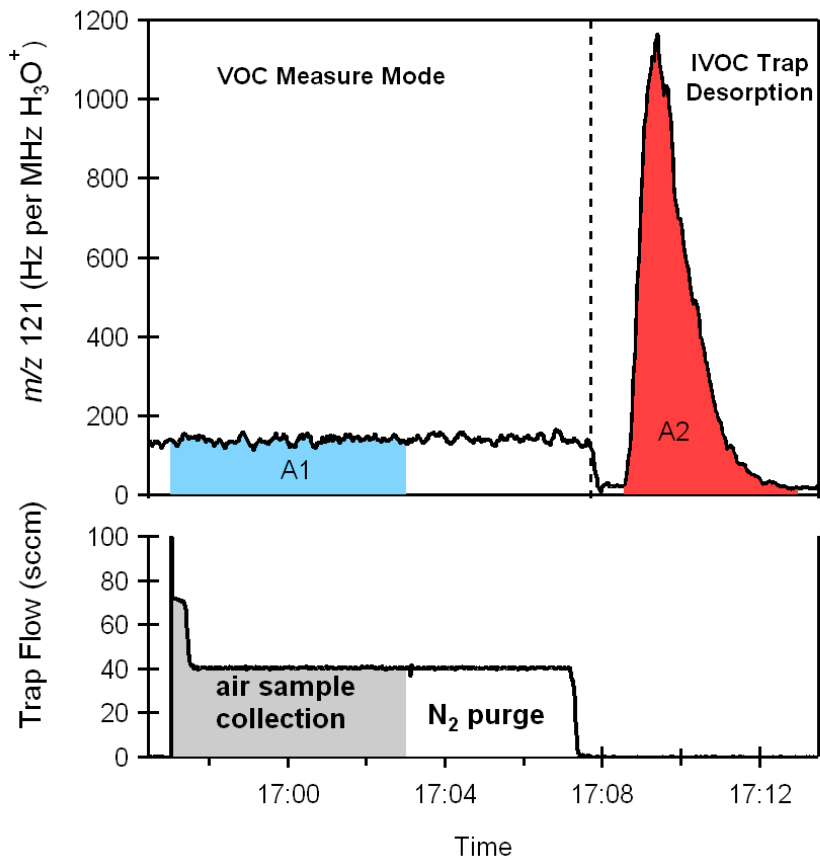

Fig. 7. Upper panel shows a time series of the 1,3,5trimethylbenzene ion signal $(\mathrm{m} / \mathrm{z}, 121)$ from a prepared test mixture as measured in VOC mode passing through the water trap and from desorption of a $257 \mathrm{cc}$ air sample of the test mixture collected on the Tenax trap (A2 red shading). The bottom panel shows the gas flow through the Tenax trap. The shaded area A1 in VOC mode corresponds to the IVOC sample collection time.

for the air volume sampled:

IVOC : $X_{i}=\left[\frac{\mathrm{AC}_{(i)}-\operatorname{bkgAC}_{(i)}}{\mathrm{nAC}_{(i)} \times \mathrm{MHzH}_{3} \mathrm{O}^{+}}\right] /$moles air sample,

where $\mathrm{AC}$ represents the area under the sample ion peak, bkgAC the background area, and $\mathrm{nAC}$ is the sensitivity of the PTR-MS to the compound $i$ in units of area counts per nmol. Since the drift tube kinetics do not change between VOC and IVOC modes, the intrinsic sensitivities are the same, and $\mathrm{nAC}$ sensitivities can be calculated from ncps values. For example, a nominal VOC sensitivity of $10 \mathrm{~Hz} \mathrm{ppbv}^{-1}$ per $\mathrm{MHz}$ $\mathrm{H}_{3} \mathrm{O}^{+}$and a $25 \mathrm{sccm}$ flow into the drift tube yields an $80 \mathrm{Td}$ nAC sensitivity value of $5.4 \times 10^{5}$ area counts nmol ${ }^{-1}$ per $\mathrm{MHz} \mathrm{H}_{3} \mathrm{O}^{+}$at $80 \mathrm{Td}$. For n-dodecane the sensitivity shown in Fig. 3 of 1.7 ncps yields an nAC sensitivity of $9.14 \times 10^{4}$ area counts nmol ${ }^{-1}$ per $\mathrm{MHz} \mathrm{H}_{3} \mathrm{O}^{+}$, or 538 area counts $\mathrm{ng}^{-1}$ per $\mathrm{MHz} \mathrm{H}_{3} \mathrm{O}^{+}$.

\subsection{VOC discrimination}

By purging the Tenax trap before desorption, the light alkenes and other VOCs can be removed to make identification of IVOC alkanes and other species tractable. Several desorption purge temperatures were tested to find the optimum temperature for VOC discrimination without significant loss of IVOC alkane species. A $150{ }^{\circ} \mathrm{C}$ purge temperature was chosen as this provided effective removal of interfering VOC compounds while limiting losses of $\mathrm{C}_{12}$ and larger alkanes. Figure 8 shows an example of the effectiveness of the trap purge for several species. Methacrolein, benzene, toluene, p-xylene, 1,2,4-trimethylbenzene, 1,2,3,5tetramethylbenzene, decane, dodecane, and pentadecane were sampled onto the trap and subjected to two purge temperatures of $30^{\circ} \mathrm{C}$ and $150^{\circ} \mathrm{C}$. Given the breakthrough volumes for these compounds, no loss would be expected for the $30^{\circ} \mathrm{C}$ purge and this temperature was used as a reference to compare to other desorption temperatures. Methacrolein, benzene and toluene were removed by the $150{ }^{\circ} \mathrm{C}$ purge flow with $98 \pm 7 \%, 99 \pm 5 \%$ and $97 \pm 5 \%$ reduction in their respective peak areas. The purge flow at $150{ }^{\circ} \mathrm{C}$ effectively removed alkanes and alkenes $<\mathrm{C}_{9}$ and n-aldehydes $<\mathrm{C}_{7}$. Decane, dodecane, and pentadecane peak areas were reduced by $84 \%$, $52 \%$, and $7.5 \%$, respectively. The noticeable offset of the pentadecane desorption peaks in Fig. 8 is due to the migration of pentadecane further along the Tenax adsorbent bed with the $150{ }^{\circ} \mathrm{C}$ purge flow. The IVOC thermal desorption sampler thus measures alkanes from the $\mathrm{C}_{12}-\mathrm{C}_{18}$ range with the upper range limited by the ability to effectively transfer low volatility compounds through PTR-MS sample lines and valves.

Given the complexity of alkane composition in diesel fuel and exhaust, whole diesel fuel might be a good standard to calibrate PTR-MS sensitivity to alkanes. Using the mass composition of alkanes in diesel fuel reported by Gentner et al. (2012), a sensitivity of $1.0 \mathrm{ncps}$ at $80 \mathrm{Td}$ was determined from the sum of the $\mathrm{C}_{n} \mathrm{H}_{2 n+1}$ ion response from $m / z 57$ to 113 observed for diesel fuel evaporated in the dynamic dilution system and measured by the IVOC sampler under the $150^{\circ} \mathrm{C}$ purge condition. Since alkanes $<\mathrm{C}_{11}$ are either completely or mostly removed in the purge, this value represents the method sensitivity to IVOC alkanes at $80 \mathrm{Td}$ and was used to estimate IVOC alkane abundance in exhaust. This value is in reasonable accord with the $\mathrm{n}$-alkane sensitivity values shown in Fig. 3. A higher sensitivity of $1.5 \mathrm{ncps}$ was obtained from the $m / z 57$ to 213 mass range, illustrating that significant ion signal occurred at higher masses.

Figure 9 illustrates the discrimination against light alkenes and unsaturated carbonyls in engine exhaust by the thermal desorption sampler. Shown in the figure is a time series of the $\mathrm{C}_{n} \mathrm{H}_{2 n+1}$ ion group response associated with these compounds and larger alkanes present in diesel and gasoline engine exhaust. The exhausts were analyzed by alternating between VOC mode sampling using a $-30^{\circ} \mathrm{C}$ dehumidifier and IVOC mode sampling using $150^{\circ} \mathrm{C}$ purge to remove volatile compounds. The IVOC sample size was $135 \mathrm{~mL}$. The same suite of ions was measured in both modes with dwell times for $m / z 43,57,71,85$, and 99 of $50 \mathrm{~ms}$ and dwell times for $\mathrm{m} / \mathrm{z} 113$ and 127 of $100 \mathrm{~ms}$. The exhausts were diluted by a similar amount so the ion signals would reflect differences in absolute organic compound emission rates from these 

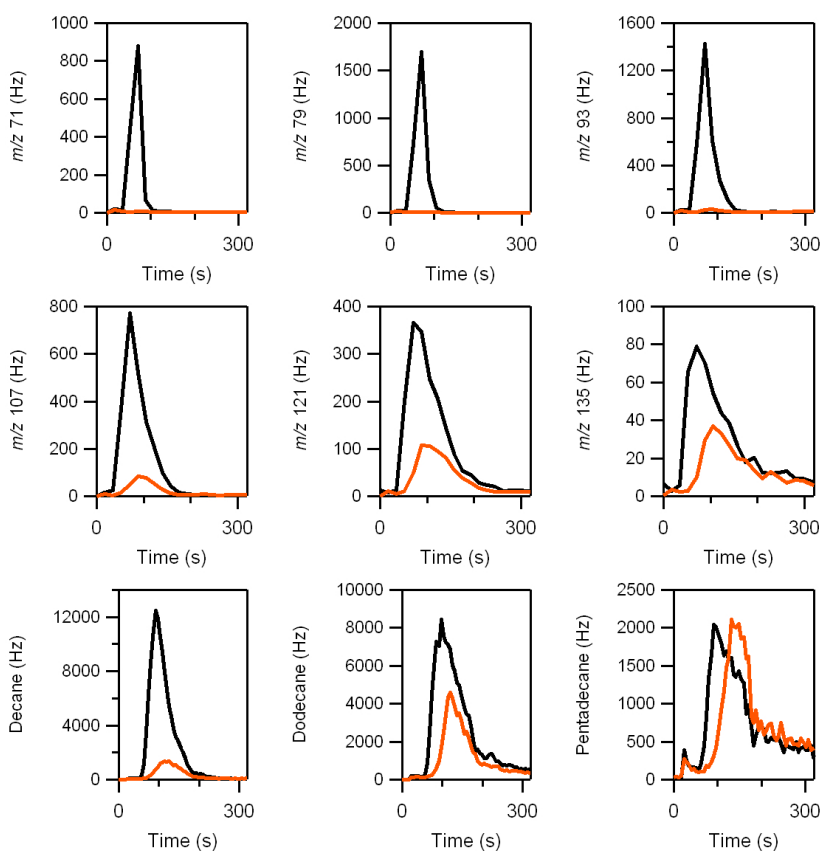

Fig. 8. PTR-MS IVOC mode desorption peaks of selected compounds for $30^{\circ} \mathrm{C}$ (blue trace) and $150{ }^{\circ} \mathrm{C}$ purge (red trace) temperatures: methacrolein $(\mathrm{m} / \mathrm{z} 71)$, benzene $(\mathrm{m} / \mathrm{z} 79)$, toluene $(\mathrm{m} / \mathrm{z} 93)$, p-xylene $(m / z, 107), 1,2,4$-trimethylbenzene $(\mathrm{m} / \mathrm{z}, 121)$ and 1,2,3,5tetramethylbenzene $(\mathrm{m} / \mathrm{z} 135)$, decane $(\mathrm{m} / \mathrm{z} 57,71,85,99)$, dodecane $(m / z 57,71,85,99)$, and pentadecane $(m / z 57,71,85,99)$. The ion signal $(\mathrm{Hz})$ is normalized to $\mathrm{MHz} \mathrm{H}_{3} \mathrm{O}^{+}$.

engines. Much higher VOC mode responses were observed in gasoline exhaust for the lighter ions $m / z 43,57,71,85$. Since aldehyde emissions are much less prominent in gasoline engine exhaust and isobaric interferences from unsaturated aldehydes (i.e., acrolein, crotonaldehyde, methacrolein) are not as significant as in diesel exhaust (Schauer et al., 1999, 2002), the ion response was attributed to emissions of propene, butenes, pentenes, and hexenes, respectively. In IVOC mode the signal for these ions is greatly diminished because these volatile alkenes and unsaturated aldehydes are effectively purged from the trap before desorption into the drift tube. The small remaining signal was attributed to the IVOC alkanes. The IVOC mode ion signal for the larger alkane ions $m / z$ 99, 113, 127 was more prominent relative to the VOC mode signal. The $m / z 127$ ion displayed a greater response in diesel exhaust, consistent with larger mass emissions of $>\mathrm{C}_{12}$ alkanes in diesel exhaust than gasoline exhaust (Schauer et al., 1999, 2002).

In summary, for mixtures of gasoline and diesel engine exhaust as found in urban air, attributing the $\mathrm{C}_{n} \mathrm{H}_{2 n+1}$ signal to IVOC alkanes is complicated by large emission rates of light alkenes associated with gasoline engine exhaust and the large emission rates of the unsaturated $\mathrm{C}_{3}-\mathrm{C}_{4}$ aldehydes acrolein, crotonaldehyde, methacrolein emitted in diesel engine exhaust. These VOCs could be purged from the Tenax trap and
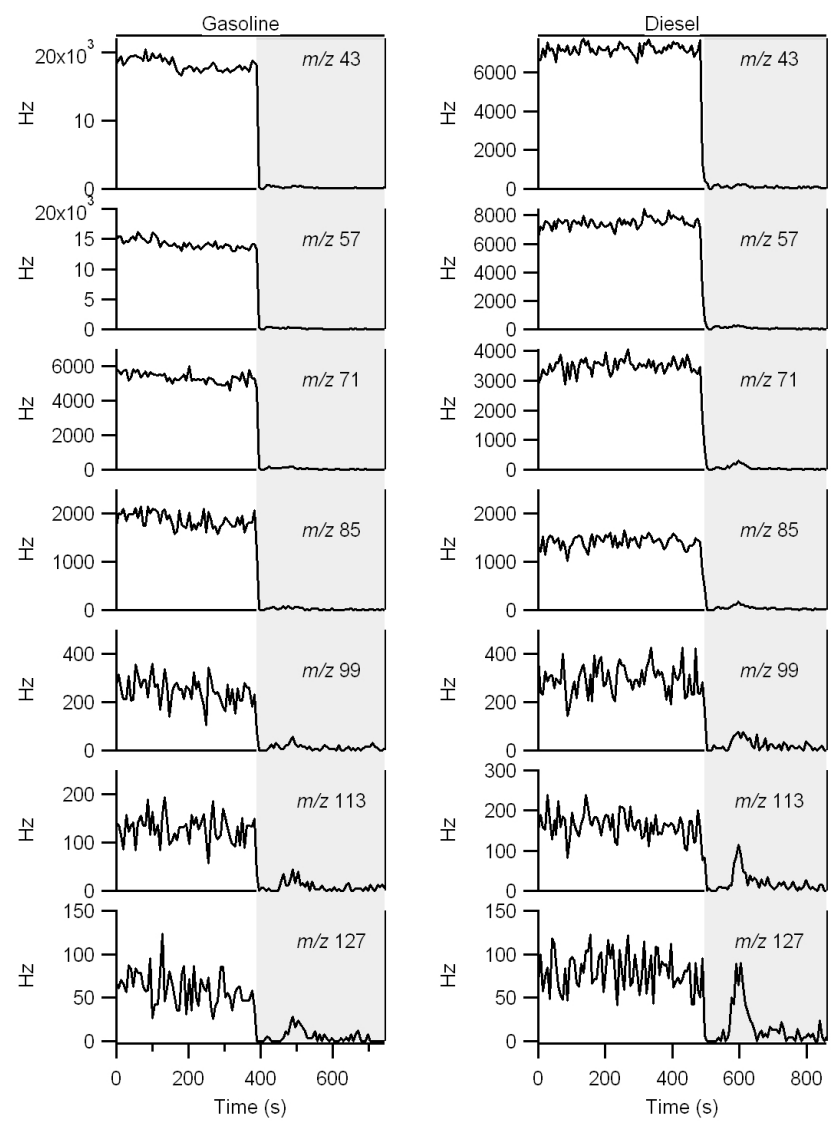

Fig. 9. Time series of measurements showing VOC and IVOC signals in gasoline (left) and diesel (right) exhaust. The IVOC mode signal is indicated by the gray shaded area. The ion signal $(\mathrm{Hz})$ is normalized to $\mathrm{MHz} \mathrm{H}_{3} \mathrm{O}^{+}$.

the resulting thermal desorption $\mathrm{C}_{n} \mathrm{H}_{2 n+1}$ signal was interpreted as resulting from long chain alkanes associated with diesel engine exhaust. The IVOC sampling mode purge removes alkanes and alkenes $<\mathrm{C}_{11}$ before desorption. Alkenes $\geq \mathrm{C}_{11}$ have not been reported in gasoline or diesel engine exhaust. In gasoline engine exhaust, $\geq \mathrm{C}_{11}$ alkanes constitute $\sim 0.1 \%$ of the total gas phase organic compound mass emission rate (Schauer et al, 1999). In diesel exhaust, $\geq \mathrm{C}_{11}$ alkanes constitute $\sim 2.5 \%$ of the identified alkane emission rate but we note here that $\sim 20 \%$ of the total mass emission rate was unidentified complex material (Schauer et al., 1999), which is likely comprised of $>\mathrm{C}_{11}$ branched alkanes. The total long chain alkane mass emission rate is underestimated due to incomplete characterization by gas chromatography methods. This analytical knowledge gap could potentially be bridged by the TD-PTR-MS sampling methodology. 


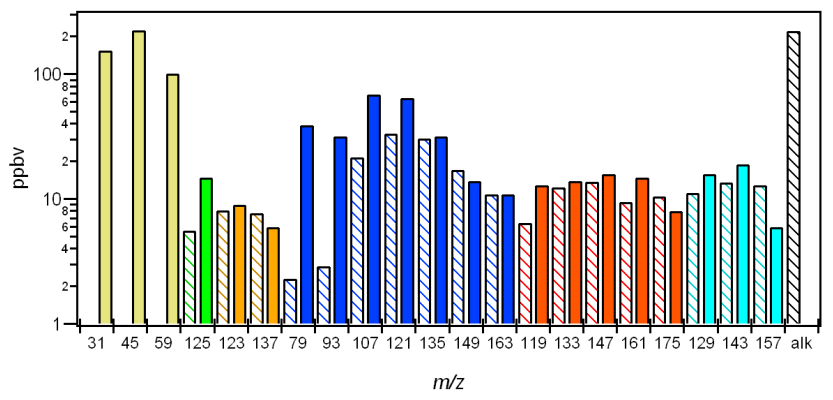

Fig. 10. Molar mixing ratio abundance of compounds measured in diluted diesel exhaust by VOC (solid bars) and IVOC (striped bars) sampling modes at $80 \mathrm{Td}$ arranged by compound class: oxygenated compounds (gold bars), cycloalkanes (green), bicyloalkanes (orange), alkylbenzenes (blue), naphthenic monoaromatics (red), naphthalenes (teal). Total IVOC alkane abundance is shown as separate bar labeled alk.

\subsection{Vehicle exhaust IVOC mixing ratios and source fingerprint}

Sensitivities were applied to convert VOC and IVOC mode data from diesel exhaust sampling at $80 \mathrm{Td}$ into molar mixing ratios (ppbv). Sensitivities were determined from calibrations from a gas standard or dynamic dilution experiments. For compounds that were not readily available, the sensitivity was estimated from compounds with a known response and similar mass by accounting for differences in the calculated collisional rate constants (Su, 1988). Mixing ratios of selected species in diluted diesel exhaust are shown as a bar graph in Fig. 10. Mixing ratios of trimethyl cycloalkanes $(\mathrm{m} / \mathrm{z} 125)$ and bicycloalkanes were calculated assuming a nominal collisional rate constant of $2 \times 10^{-9} \mathrm{~cm}^{3}$ molecule $\mathrm{s}^{-1}$, a reasonable assumption based on lab tests of compound response. The mixing ratio pattern observed in the IVOC mode in Fig. 10 illustrates discrimination against the volatile species and comparable mixing ratios to those measured in VOC mode for higher molecular weight compounds. The light alkylbenzenes $(\mathrm{m} / z 79,93)$ were essentially removed with the $150^{\circ} \mathrm{C}$ purge, so the limited response was attributed to fragmentation of larger alkylbenzenes. The difference between VOC and IVOC mixing ratios at $m / z 79,93,107$, and 121 was $97 \%, 95 \%, 80 \%$, and $63 \%$, respectively, which were similar to the corresponding removal rates observed in Fig. 8 of $99 \%, 97 \%, 86 \%$, and $65 \%$. The $\mathrm{C}_{5}$ and $\mathrm{C}_{6}$-alkylbenzene compounds $(\mathrm{m} / \mathrm{z} 149$, 163) mixing ratios were similar in both the VOC and IVOC measuring modes. These compounds would not be removed from the trap purge at $150^{\circ} \mathrm{C}$; the agreement between these modes indicates that these compounds were also not removed in the cold trap at these mixing ratios. Good agreement was also observed for the bicycloalkane responses at $m / z 123$ and 137 and the naphthenic monoaromatic responses at $m / z 133$ and 147 , with the IVOC mixing ratios being within $15 \%$ of

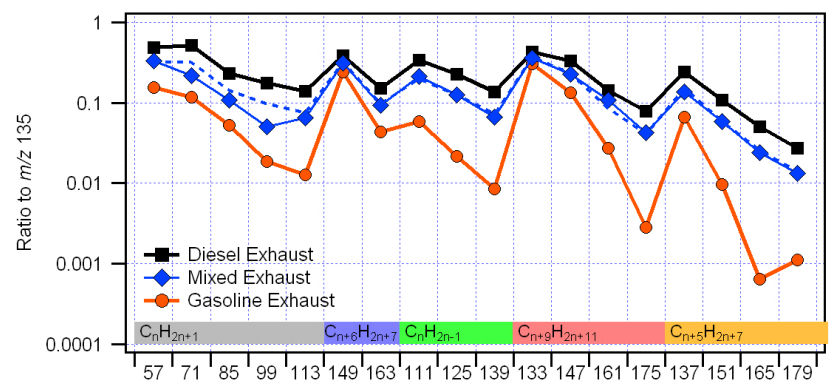

$\mathrm{m} / \mathrm{z}$

Fig. 11. PTR-MS IVOC mode exhaust fingerprints observed for diesel exhaust (black squares), gasoline exhaust (red circles), and an approximately 50:50 mixture (blue diamonds). The dashed line is a calculated exhaust fingerprint of a 50:50 mixture of gasoline and diesel exhaust given the source profiles shown. Color bands indicate compound group: alkane fragment ions (gray), alkylbenzenes (blue); cycloalkane fragment ions (green), naphthenic monoaromatics (red); bicycloalkanes (orange).

the VOC mixing ratios. For the naphthenic monoaromatic ion $m / z 175$ and the dimethyl naphthalene ion $m / z$ 157, the IVOC mode response was larger than the VOC mode by $40 \%$ and $130 \%$, respectively, indicating losses of these heavier compounds to the water trap.

The total IVOC alkane mixing ratio was determined from summing up the $m / z 57,71,85,99$, and 113 thermal desorption ion responses and applying the diesel fuel-based sensitivity factor 1.0 ncps. Uncertainty in the fuel-based alkane sensitivity arises from uncertainty in the reported molar abundance of alkanes by carbon number (not well quantified in the literature), the potential for interfering ion fragments from other compound groups (thought to be small), and in assuming that the molar abundance of alkanes in fuel is similar to that found in exhaust. The calculated IVOC alkane mixing ratio of $220 \mathrm{ppbv}$ is similar to the sum total of the $\mathrm{C}_{1}-\mathrm{C}_{4}$ alkylbenzenes $(\mathrm{m} / \mathrm{z}, 93,107,121,135)$ mixing ratio of 198 ppbv. This data can be compared to that reported by Schauer et al. (1999), where the molar ratio of the total $C_{12}$ to $\mathrm{C}_{18} \mathrm{n}$-alkane emission rates to the reported $\mathrm{C}_{1}-\mathrm{C}_{3}$ alkylbenzene compound emission rates was 0.20 . In our experiment the ratio of the IVOC alkane mixing ratio to the total $\mathrm{C}_{1}-\mathrm{C}_{3}$ alkylbenzene $(\mathrm{m} / z, 93,107,121)$ mixing ratio was 1.3 . The difference could be attributed to the presence of branched $\mathrm{C}_{12}-\mathrm{C}_{18}$ alkanes that would be measured by the PTR-MS, but were not reported by Schauer et al. (1999) and therefore likely part of the unresolved complex material mass that represented $20 \%$ of the total organic mass emissions rate. It is also interesting to compare the alkylbenzene abundance to the other aromatic compound groups. The sum total of the major naphthenic monoaromatic compounds $(\mathrm{m} / z 119$, $133,147,161,175)$ was $66 \mathrm{ppbv}$, and sum total of naphthalene group $(m / z 129,143,157)$ was $41 \mathrm{ppbv}$. Together these 
compounds account for about half the molar abundance of the more routinely measured VOC alkylbenzene compounds.

Figure 11 displays the IVOC thermal desorption peak area response for selected ions relative to that of $m / z$ 135. The $\mathrm{m} / z 135$ ion, attributed to $\mathrm{C}_{4}$-alkylbenzene compounds, is abundant in both diesel and gasoline exhaust. A clear difference was observed between the diesel and gasoline exhaust relative abundance. In general, the gasoline exhaust ratios to $m / z 135$ were a factor of 10 lower than the diesel exhaust, reflecting the larger mass emission rate of higher molecular weight compounds in diesel exhaust. The relative abundance pattern for each engine exhaust type can potentially be used as a source fingerprint to quantify the relative contributions of diesel and gasoline engine exhausts to organic compound concentrations in urban air. For this study, it was found that a mixture containing diesel and gasoline engine exhaust yielded compound abundance ratios between the two pure exhaust source ratios, as shown in the figure. The observed exhaust mixture ratio could be reasonably well estimated from the source ratios as defined by the following equations:

$R_{i}=\left(x \times D_{i}\right)+\left(y \times G_{i}\right)$

$x+y=1$

where $R_{i}$ is the observed ratio at $\mathrm{m} / z$ mass $i, D_{i}$ and $G_{i}$ are the exhaust fingerprint ratios observed in the diesel and gasoline exhaust at mass $i$, and $x$ and $y$ are the respective fractions of diesel and gasoline exhaust in the mixture. For example, Fig. 11 shows observed ratios of 50:50 mixture of diesel and gasoline engine exhaust and a fit based on Eq. (3) using $x$ and $y=0.5$. The good agreement suggests there is the potential to quantify the relative contributions of diesel and gasoline engine exhausts in urban air using IVOC compound measurements by PTR-MS.

\section{Conclusions}

Analysis of gasoline and diesel fuel and gasoline and diesel engine exhaust was performed to determine if the PTR-MS instrument could be used to quantify long chain alkanes and other IVOC compounds associated with diesel exhaust emissions. Laboratory experiments show the PTR-MS sensitivity to n-alkanes increased with compound carbon number with negligible sensitivity to n-alkanes smaller than $\mathrm{C}_{8}$. For larger $\mathrm{n}$-alkanes, the sensitivity was much less than expected if these compounds react at the collisional rate limit with $\mathrm{H}_{3} \mathrm{O}^{+}$. Sensitivities did not increase with decreasing drift tube Townsend number, suggesting the proton transfer reaction with larger alkanes is endothermic. The n-alkanes fragment to a common set of ions with formula $\mathrm{C}_{n} \mathrm{H}_{2 n+1}$ as well as $m / z 41$. The relative intensity of the fragment ions was a function of drift field strength; at lower Townsend values more ion intensity occurred in larger masses and some branched alkanes yielded significant $M-1$ ions. Laboratory tests of fragmentation patterns suggested that cycloalkanes $(m / z 83,97,111,125)$ and naphthenic monoaromatics $(m / z 119,133,147$, etc. $)$ were important constituents in both fuel and exhaust.

A thermal desorption sampler was added to the PTR-MS drift tube, allowing for normal VOC measurements as well as sample collection and desorption of heavier organics from a Tenax TA adsorbent trap. In this analytical approach the PTR-MS drift tube was operated at $80 \mathrm{Td}$ for both VOC sampling and thermal desorption analysis to reduce fragmentation. The thermal desorption sampler discriminated against VOC compounds by using a high temperature purge before direct desorption into the PTR-MS drift tube using dry $\mathrm{N}_{2}$ carrier gas. By implementing a purge, VOC compounds that would interfere with the measurement of $\mathrm{C}_{12}-\mathrm{C}_{18}$ long chain alkanes were removed. Diesel fuel was used to calibrate the thermal desorption sampler sensitivity to total alkanes in the $\mathrm{C}_{11}-\mathrm{C}_{18}$ range, yielding a value of $1.0 \mathrm{~Hz} \mathrm{ppbv}^{-1}$ per $\mathrm{MHz} \mathrm{H}_{3} \mathrm{O}^{+}$from summation of the $\mathrm{C}_{n} \mathrm{H}_{2 n+1}$ ion responses from $m / z 57$ to 113 . In diluted diesel engine exhaust, IVOC alkane mixing ratios were measured to be similar to the sum total of $\mathrm{C}_{1}-\mathrm{C}_{4}$ alkylbenzene abundance, and therefore comprise a significant amount of precursor material for secondary organic aerosol formation. Thermal desorption sampling along with low Townsend number PTR-MS analysis appears to be a viable approach for providing quantitative information on the total abundance of long chain alkanes and aromatics species in diesel exhaust. The abundance patterns of IVOC compounds may in fact allow for emission profiles to be developed to better quantify the relative contributions of diesel and gasoline exhaust emissions to urban air concentrations of organic compounds.

Acknowledgements. The authors would like to thank Jake McDonald and staff at LRRI. This research was supported by the Office of Science (BER) U.S. Department of Energy, grant no. DE-FG0208ER64626, and the National Science Foundation AGS program grant no. 1140176 . This publication was made possible by USEPA grant (RD-83479601-0). Its contents are solely the responsibility of the grantee and do not necessarily represent the official views of the USEPA. Further, USEPA does not endorse the purchase of any commercial products or services mentioned in the publication.

Edited by: N. Yassaa

\section{References}

Arnold, S. T., Viggiano, A. A., and Morris, R. A.: Rate Constants and Product Branching Fractions for the Reactions of $\mathrm{H}_{3} \mathrm{O}^{+}$and $\mathrm{NO}^{+}$with $\mathrm{C}_{2}-\mathrm{C}_{12}$ Alkanes, J. Phys. Chem. A, 102, 8881-8887, 1998.

Bahreini, R., Middlebrook, A. M., de Gouw, J. A., Warneke, C., Trainer, M., Brock, C. A., Stark, H., Brown, S. S., Dube, W. P., Gilman, J. B., Hall, K., Holloway, J. S., Kuster, W. C., Perring, 
A. E., Prevot, A. S. H., Schwarz, J. P., Spackman, J. R., Szidat, S., Wagner, N. L., Weber, R. J., Zotter, P., and Parrish, D. D.: Gasoline emissions dominate over diesel in formation of secondary organic aerosol mass, Geophys. Res. Lett., 39, L06805, doi:10.1029/2011GL050718, 2012.

Bohme, D. K., Mackay, G. I., and Tanner, S. D.: An Experimental Study of the Gas-Phase Kinetics of Reactions with Hydrated $\mathrm{H}_{3} \mathrm{O}^{+}$Ions $(n=1-3)$ at $298 \mathrm{~K}$, J. Am. Chem. Soc., 101, 37243730, 1979.

Dallmann, T. R. and Harley, R. A.: Evaluation of mobile source emission trends in the United States, J. Geophys. Res., 115, D14306, doi:10.1029/2010JD013862, 2010.

Dzepina, K., Volkamer, R. M., Madronich, S., Tulet, P., Ulbrich, I. M., Zhang, Q., Cappa, C. D., Ziemann, P. J., and Jimenez, J. L.: Evaluation of recently-proposed secondary organic aerosol models for a case study in Mexico City, Atmos. Chem. Phys., 9, 5681-5709, doi:10.5194/acp-9-5681-2009, 2009.

Gentner, D. R., Isaacman, G., Worton, D. R., Chan, A. W. H., Dallmann, T. R., Davis, L., Liu, S., Day, D. A., Russell, L. M., Wilson, K. R., Weber, R., Guha, A., Harley, R. A., and Goldstein, A. H.: Elucidating secondary organic aerosol from diesel and gasoline vehicles through detailed characterization of organic carbon emissions, P. Natl. Acad. Sci., 109, 18318-18323, 2012.

de Gouw, J. A., Middlebrook, A. M., Waneke, C., Goldan, P. D., Kuster, W. C., Roberts, J. M., Fehsenfeld, F. C., Worsnop, D. R., Canagaratna, M. R., Pszenny, A. A., Keene, W. C., Marchewka, M., Bertman, S. B., and Bates, T. S.: Budget of organic carbon in a polluted atmosphere: Results from the New England Air Quality Study in 2002, J. Geophys. Res., 110, D16305, doi:10.1029/2004JD005623, 2005.

Han, M., Assanis, D. N., Jacobs, T. J., and Bohac, S. V.: Method and detailed analysis of individual hydrocarbon species from diesel combustion modes and diesel oxidation catalyst, J. Eng. Gas. Turbines. Power, 130, 042803, doi:10.1115/1.2900728, 2008.

Health Effects Institute (HEI): Traffic related air pollution: A critical review of the literature of emissions, exposure, and health effects, Special Report \# 17, Health Effects Institute, Boston, Massachusetts, 2010.

Hodzic, A., Jimenez, J. L., Madronich, S., Canagaratna, M. R., DeCarlo, P. F., Kleinman, L., and Fast, J.: Modeling organic aerosols in a megacity: potential contribution of semi-volatile and intermediate volatility primary organic compounds to secondary organic aerosol formation, Atmos. Chem. Phys., 10, 5491-5514, doi:10.5194/acp-10-5491-2010, 2010.

Hoekman, S. K.: Speciated Measurements and Calculated Reactivities of Vehicle Exhaust Emissions from Conventional and Reformulated Gasolines, Environ. Sci. Technol., 26, 1206-1216, 1992.

Hunter, K. C. and East, A. L. L.: Properties of C-C Bonds in nAlkanes: Relevance to Cracking Mechanisms, J. Phys. Chem. A., 106, 1346-1356, 2002.

Isaacman, G., Wilson, K. R., Chan, A. W. H., Worton, D. R., Kimmel, J. R., Nah, T., Hohaus, T., Gonin, M., Kroll, J. H., Worsnop, D. R., and Goldstein, A. H.: Improved Resolution of Hydrocarbon Structures and Constitutional Isomers in Complex Mixtures Using Gas Chromatography-Vacuum Ultraviolet-Mass Spectrometry, Anal. Chem., 84, 2335-2342, doi:10.1021/ac2030464, 2012.

Jobson, B. T. and McCoskey, J. K.: Sample drying to improve $\mathrm{HCHO}$ measurements by PTR-MS instruments: laboratory and field measurements, Atmos. Chem. Phys., 10, 1821-1835, doi:10.5194/acp-10-1821-2010, 2010.

Jobson, B. T., Alexander, M. L., Maupin, G. D., and Muntean, G. G.: On-line analysis of organic compounds in diesel exhaust using a proton transfer reaction mass spectrometer (PTR-MS), Int. J. Mass. Spectrom., 245, 78-89, 2005.

Jordan, C. E., Ziemann, P. J., Griffin, R. J., Lim Y. B., Atkinson, R., and Arey, J.: Modeling SOA formation from $\mathrm{OH}$ reactions with $\mathrm{C}_{8}-\mathrm{C}_{17}$ n-alkanes, Atmos. Environ., 42, 8015-8026, 2008.

Kleinman, L. I., Springston, S. R., Daum, P. H., Lee, Y.-N., Nunnermacker, L. J., Senum, G. I., Wang, J., Weinstein-Lloyd, J., Alexander, M. L., Hubbe, J., Ortega, J., Canagaratna, M. R., and Jayne, J.: The time evolution of aerosol composition over the Mexico City plateau, Atmos. Chem. Phys., 8, 1559-1575, doi:10.5194/acp-8-1559-2008, 2008.

Lewis, A. C., Carslaw, N., Marriott, P. J., Kinghorn, R. M., Morrison, P., Lee, A. L., Bartle, K. D., and Pilling, M. J.: A larger pool of ozone forming carbon compounds in urban atmospheres, Nature, 405, 778-781, 2000.

Lias, S. G., Liebman, J. F., and Levin, R. D.: Evaluated Gas Phase Basicities and Proton Affinities of Molecules; Heats of Formation of Protonated Molecules, J. Phys. Chem. Ref. Data, 13, 695808, 1984.

Lim, Y. B. and Ziemann, P. J.: Products and Mechanism of Secondary Organic Aerosol Formation from Reactions of n-Alkanes with $\mathrm{OH}$ radicals in the Presence of $\mathrm{NO}_{\mathrm{x}}$, Environ. Sci. Technol., 39, 9229-9236, 2005.

Lough, G. C., Schauer, J. J., Lonneman, W. A., and Allen, M. K.: Summer and Winter Nonmethane Hydrocarbon Emissions from On-Road Motor Vehicles in the Midwestern United States, Air \& Waste Manage. Assoc., 55, 629-646, 2005.

McDonald, J. R., Barr, E. B., White, R. K., Chow, J. C., Schauer, J. J., Zielinska, B., and Grosjean, E.: Generation and characterization of four dilutions of diesel engine exhaust for a subcronic inhalation study, Environ. Sci. Technol., 38, 2513-2522, 2004.

McDonald, J. D., Reed, M. D., Campen, M. J., Barrett, E. G., Seagrave, J., and Mauderly, J. L.: Health effects of inhaled gasoline engine emissions, Inhal. Toxicol., 19, 107-116, 2007.

McDonald, J. D., Campen, M. J., Harrod, K. S., Seagrave, J., Seilkop, S. K., and Mauderly, J. L.: Engine-operating load influences diesel exhaust composition and cardiopulmonary and immune responses, Environ. Health Persp., 119, 1136-1141, 2011.

Meng, Z., Dabdudb, D., and Seinfeld, J. H.: Chemical coupling between atmospheric ozone and particulate matter, Science, 299, 116-119, 1997.

Murphy, B. N. and Pandis, S. N.: Simulating the formation of semivolatile primary and secondary organic aerosol in a regional chemical transport model, Environ. Sci. Technol., 43, 47224728, 2009.

Parrish, D. A., Kuster, W. C., Shao, M., Yokouchi, Y., Kondo, Y., Goldan, P. D., deGouw, J. A., Koike, M., and Shirai, T.: Comparison of air pollutant emissions among mega-cities, Atmos. Environ., 43, 6435-6441, 2009.

Presto, A. A., Miracolo, M. A., Kroll, J. H., Worsnop, D. R., Robinson, A. L., and Donahue, N. M.: Intermediate- Volatility Organic Compounds: A Potential Source of Ambient Oxidized Organic Aerosol, Environ. Sci. Technol., 43, 4744-4749, 2009. 
Pye, H. O. T. and Seinfeld, J. H.: A global perspective on aerosol from low-volatility organic compounds, Atmos. Chem. Phys., 10, 4377-4401, doi:10.5194/acp-10-4377-2010, 2010.

Robinson, A. L., Donahue, N. M., Shrivastava, M. K., Weitkamp, E. A., Sage, A. M., Grieshop, A. P., Lane, T. E., Pierce, J. R., and Pandis, S. N.: Rethinking Organic Aerosol: Semivolatile Emissions and Photochemical Aging, Science, 315, 1259-1262, 2007.

Samy, S. and Zielinska, B.: Secondary organic aerosol production from modern diesel engine emissions, Atmos. Chem. Phys., 10, 609-625, doi:10.5194/acp-10-609-2010, 2010.

Schauer, J. J., Kleeman, M. J., Cass, G. R., and Simoneit, B. R. T.: Measurement of Emissions from Air Pollution Sources. 2. C1 through C30 Organic Compounds from Medium Duty Diesel Trucks, Environ. Sci. Technol., 33, 1578-1587, 1999.

Schauer, J. J., Kleeman, M. J., Cass, G. R., and Simoneit, B. R. T.: Measurement of Emissions from Air Pollution Sources. 5. C1 through C32 Organic Compounds from Gasoline-Powered Motor Vehicles, Environ. Sci. Technol., 36, 1169-1180, 2002.

Schmitz, T., Hassel, D., and Weber, F.-J.: Determination of VOCcomponents in the exhaust of gasoline and diesel passenger cars, Atmos. Environ., 34, 4639-4647, 2000.

Schneidemesser, E., Monks, P. S., and Plass-Duelmer, C.: Global compariosn of VOC and CO observations in urban areas, Atmos. Environ., 44, 5053-5064, 2010.

Shirvastava, M. K., Lane, T. E., Donahue, N. M., Pandis, S. N., and Robinson, A. L.: Effects of gas particle partitioning and aging of primary emissions on urban regional and organic aerosol concentrations, J. Geophys. Res., 113, D18301, doi:10.1029/2007JD009735, 2008.

Siegl, W. O., Hammerle, R. H., Herrmann, H. M., Wenclawiak, B. W., and Luers-Jongen, B.: Organic emissions profile for a lightduty diesel vehicle, Atmos. Environ., 33, 797-805, 1999.

Smith, D., Cheng, P., and Spanel, P.: Analysis of petrol and diesel vapor and vehicle engine exhaust gases using selected ion flow tube mass spectrometry, Rapid Commun. Mass Spectrom., 16, 1124-1134, 2002.

Spanel, P. and Smith, D.: Selected ion flow tube studies of the reactions of $\mathrm{H}_{3} \mathrm{O}^{+}, \mathrm{NO}^{+}$, and $\mathrm{O}_{2}^{+}$with several aromatic and aliphatic hydrocarbons, Int. J. Mass Spectrom., 181, 1-10, 1998.
Su, T.: Erratum: Trajectory calculations of ion-polar molecule capture rate constants at low temperatures, J. Chem. Phys., 89, 5355, doi:10.1063/1.455750, 1988.

Thornberry, T., Murphy, D. M., Thomson, D. S., de Gouw, J., Warneke, C., Bates, T. S., Quinn, P. K., and Coffman, D.: measurement of aerosol organic compounds using a novel collection/thermal-desorption PTR-ITMS instrument, Aerosol Sci. Technol., 43, 486-501, 2009.

Tkacik, D. S., Presto, A. A., Donahue, N. M., and Robinson, A. L.: Secondary Organic Aerosol Formation from Intermediate-Volatility Organic Compounds: Cyclic, Linear, and Branched Alkanes, Environ. Sci. Technol, 46, 8773-8781, doi:10.1021/es301112c, 2012.

Vendeuvre, C., Ruiz-Guerrero, R., Bertoncini, F., Duval, L., Thiebaut, D., and Hennion, M. C.: Characterization of middledistillates by comprehensive two-dimensional gas chromatography $(\mathrm{GC} \times \mathrm{GC})$ : A powerful alternative for performing various standard analysis of middle-distillates, J. Chromatogr. A, 1086, 21-28, 2005.

Vendeuvre, C., Ruiz-Guerrero, R., Bertoncini, F., Duval, L., and Thiebaut, D.: Comprehensive Two-Dimensional Gas Chromatography for Detailed Characterisation of Petroleum Products, Oil Gas Sci. Technol., 62, 43-55, 2007.

Volkamer, R., Jimenez, J. L., San Martini, F., Dzepina, K., Zhang, Q., Salcedo, D., Molina, L. T., Worsnop, D. R., and Molina, M. J.: Secondary organic aerosol formation from anthropogenic air pollution: Rapid and higher than expected, Geophys. Res. Lett., 33, L17811, doi:10.1029/2006GL026899, 2006.

Wang, C.-Y. F., Qian, K., and Green, L. A.: GCxMS of Diesel: A Two-Dimensional Separation Approach, Anal. Chem., 77, 27772785, 2005.

Zielinska, B., Sagebiel, J. C., Harshfield, G., Gertler, A. W., and Pierson, W. R.: Volatile Organic Compounds up to C20 Emitted from Motor Vehicles; Measurement Methods, Atmos. Environ., 30, 2269-2286, 1996. 